Portland State University

PDXScholar

1977

\title{
A Model for Decision Making: A Systems Approach
}

Eleanor Weitman

Portland State University

Follow this and additional works at: https://pdxscholar.library.pdx.edu/open_access_etds

Part of the Social Work Commons, and the Theory, Knowledge and Science Commons Let us know how access to this document benefits you.

\section{Recommended Citation}

Weitman, Eleanor, "A Model for Decision Making: A Systems Approach" (1977). Dissertations and Theses. Paper 2162.

https://doi.org/10.15760/etd.2157

This Thesis is brought to you for free and open access. It has been accepted for inclusion in Dissertations and Theses by an authorized administrator of PDXScholar. Please contact us if we can make this document more accessible: pdxscholar@pdx.edu. 
A MODEL FOR DECISION MAKING: A SYSTEMS APPROACH

EIEANOR WEITMAN

PORTLAND STATE UNIVERSITY

JUNE 1977 
ACCEPTED BY

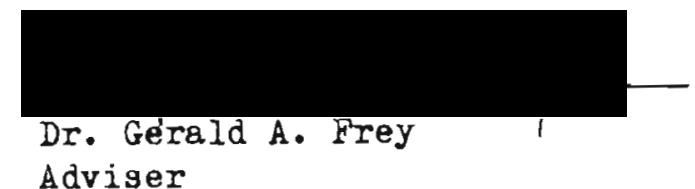


TABLE OF CONTENTS

PAGE

ACKNOW LEDGEMENTS

LIST OF TABLES . . . . . . . . . . . . . . . . . . vii

LIST OF FIGURES . . . . . . . . . . . . . . . . . . viii

CHA PTER

I THE PROBLEM OF DECISION MAKING IN SOCIAL PLANNING • 1

Introduction: The Problem ......... 1

The Purpose of Social Planning . . . . . . 3

Review of Traditional Theories . . . . . . 8

Velue Theory

Conflict Theory

Structure-Functionalism

Comparative Analysis . . . . . . . . 16

The Systems Approach .......... 19

II $\triangle$ MODEL OF THE DECISION MAKING PROCESS IN SOCIAL AGENCIES . . . . . . . . . . . . . . . 23

Elements of the Decision Process . . . . . 23

Dynamics of Interface Within Systems . . . . 27

Mechanisms for Input Reception

Output Generating Mechanisms

Coding Operations of the Subsyatem

Characteristics of Subsystems with Respect

to Change ............... 31

Limits to Model Testing.......... 33

Hypotheses Generated by the Model . . . . . 34 
III AN ANALYSIS OF TEREE BASIC SYSTEMS CODES . . . . .

A Paradigm for the Analysis of Theoretical

Construct................ .

Application of the Paradigm to General

Syatems Theory . . . . . . . . . . .

The Problem of Change and Systems Dynamics: Gregory Bateson

The Problem of Conflict in Systems: Anatole Rapaport

The System as a Whole: Ludwig von Bertlanffy

Some General Characteristics of Systems . . .

Application of the Paradigm to Information

l'heory . . . . . . . . . . . . .

Information and Communication: Norbert Weiner

The Control and Constraint of Information: Ross Ashby

The Analysis of Information Processes: Warren Weaver

Common Features of Information Theories....

Application of the Paradiom to Managerial

Theory . . . . . . . . . . . . .

Traditional Managerial Theory MBO - Management by Objective Task Force Theory: NASA

Common Features of Managerial Theories . . . 
IV AN APPLICATION OF THE MODEL TO A REORGANIZATION

REPORT IN SOCIAL SERVICE DELIVERY . . . . . . . .

Construction of an Instrument ........

Background of the Problem of Analysis.....

Examples of Documents Reflecting the

Three Codes . . . . . . . . . . . . .

- The Public/Voter-Politician/ Representative Interface

- The Politician/RepresentativePolitical/Fiscal Interface

- Bureaucratic/ManagerialLegislative/Fiscal Interface

- Bureaucratic/ManagerialBureaucratic/Delivery Interface

- Bureaucratic/Delivery-Public/ Client Interface

Analysis of Decision Alternatives . . . . .

- Alternative One: Bureaucratized DHR

- Alternative Two: No Change from Current Organization

- Altemative Three: Reorganization with Policy Non Bureaucratic

- Altemative Four: Reorganization with Limited Bureaucracy and GCOA as a Counterweight.

V TMPLICATIONS OF THE MODEL FOR SOCIAL PLANNING . .

Areas for Future Research

BIBLIOGRAPHY . . . . . . . . . . . . . . . . . . 


\section{ACKNOW LEDGEMENTS}

First and foremost I thank my family - my husband and children for their encouragement and support - over the years I've been in school. For without this I could never have proceeded this far. Dr. Jerry Frey, adviser for hours of patient reading and to Mary Foon who picked up all of the pieces and put them together in the final anuscript.

I would also like to thank Dr. Devendra Sahal, Dr. King Yee, Dr. Dave Nichols and Paul Molnar for their patience often frustrating discussions of theories and applications of General Systems Theory.

I should also like to thank Peggy Eckton, S. E. Quadrant Manager, Multnomah County, for having the confidence in me to represent her at County Management where I first became alerted to the problems of decision making at the interface of bureaucracy and politics。

To the Multnomah County Management team of DHS headed by Jewel Goddard, for their support and help during those troubled days.

To Ruth Shepherd for giving me a chance to follow-up on my ideas during this past year under her supervision.

And, to Linda Kaeser, Administrator of the PWD and her staff for all of their help and cooperation. 
II-1 Summary of Interaction Patterns in the Systemic Relationship Between Systems

III-1 Comprative Chart of the Paradigmatic Analysis of the General System Theory Authors

III-2 Comparative Chart for the Paradigmatic Analysis of Authors on Information Theory

III-3 Comparative Chart for the Paradigmatic Comparison of Authors on Management Theory

IV-1 Features of the Three Basic Systems Codes: Their Contents and Documentary Examples

IV-2 Manifest and Latent Aspects of the Reorganization of DHR Decision Processes 
LIST OF FIGURES

PAGE

Figure 1 Systemic Relationships of Three Elements 26

Figure 2 Press Releases by Governor's Committee on Aging 105

Figure 3 HARRP Returns; Partial or Full Relief, by

Household Income, Mobile Home

Figure 4 Current and Proposed Programs for the Elderly State Program on Aging

Figure 5 Summary Elderly Programs in DBR

Figure $6 \quad$ Flow Chart of Public Welfare Division

Figure 7

Bill for an Act

Figure 8

PWD Form 415B 


\section{CHAPTER I}

THE PROBLEM OF DECISION MAKING IN SOCIAL PLANNING

\section{Introduction: The Problem}

This paper addresses itself to the problem of the analysis of the decision making processes in the area of Human Resources Planning. Planning in human services has come to the fore in recent times due to a number of socio-economic conditions that were seldom considered as part of the planning effort in the implementation of service delivery. These conditions presented a unique combination of inflationary pressures that tended to limit the resource base and an economic recession that created pressures for a greater demand for services. The resultant shrinkage of the tax base, inflationary devaluation of the funds available and increasing pressure for services placed human resource planners in a difficult position with respect to decision making in the allocation of funds for services. At all levels of govemment there were decisions that retained some programs at the expense of others, cuts were made in some programs while other aspects were increased in funding, etc. Upon examination the rationale for these decisions revealed no common logic, and political interpretations alone prove at best to be post hoc for the understanding of the decision processes involved. The purpose of this paper is to develop a model that will allow the examination of the decision making process within the context of administrative change. Specifically the problem of the effect of fiscal limitations 
and constraints as they affect the operations of various state programs for the elderly in Oregon and the proposed shift in these to the Department of Human Resources will form the focus for inquiry. The model will seek to provide a means for the potential quantification of the decision processes and will generate predictions of those decisions involved in proposed administrative changes.

The underlying assumption of this approach is that the decision processes involved in a complex delivery-administrative and policy network is polywophus in nature; no single consistant set of shared assumptions or criteria for action is present throughout the entire system. In such a situation the knowledge of what factors enter into a decision process and the various different weightings given to those factors by decision makers located at different points within the decision making process should prove useful to administrators in gaining acceptance for their particular programs from political and managerial personnel who control the funding for such programs.

This paper does not aim at affecting a change in the decision process per se; the procedures that have developed over time may in fact serve a purpose (e.g., informal political relationships) that goes beyond the decision making apparatus within the area of human resources. The paper does however seek to delinate the process and to provide a potentially measurable conceptualization of that process. In doing so, it is felt that the research will have both practical value for those directly involved in the decision making process 
itself, and a theoretical value in making some of the contexts for deciaion clear and so open the way for revising some of the assumptions about managerial and political behavior that now predominate in these areas.

As noted above, the research design utilized in this paper will seek to create a potential for quantifying the decision process. Such a potential is both desirable and possible, and can provide an index with which the political outcomes for various proposals might be predicted. The process by which variables are derived and the differences in import which accme to them in different situations are discussed in the context of a model of the decision process. The model is then used to generate several hypotheses and these will be used to predict behaviors through the application of an analytical instrument derived from the model which is designed to elicit the variations in weightings for the decision variables.

\section{The Purpose of Social Planning}

Social planning is an enterprise that has grown in importance in the last several decades. All social enterprises presume some sort of planning, but a conscious effort to spell out the particular objectives of planning is a relatively new phenomenon (Neghandi, $1975: 21-38)$

As Morris and Binstock point out, social planning may be used to replace such amorphus concepts as "community organization, politics, civil education, and social action (Morris and Binstock, 
1966:3). Social planning in their conception is a more objective approach that seeks to more clearly specify its goals and objectives (Morris and Binstock, 1966:15-24).

Bolan and Nuttall see planning as a decision process that unfolds over time under the influence of a series of surrounding variables. This process is seen as occurring in various stages; each stage in turn being characterized by a varying configuration of four basic elements. As the weightings of these four elements change, the next stage emerges (Bolan and Nuttal1, 1975:36ff).

The four elements that constitute the pressures that surround a decision in the planning process are identified as: (1) role specialization; (2) formal and informal networks; (3) planning strategies and (4) ideological issues within the planning group, (Bolan and Nuttall 1975:26-32). It is in the interplay of these four elements that the various pressures that characterize the atmosphere of planning takes place. The place of decision making is important in that it is in this sphere that there is a hiatus between the technical aspects of the plan and those possibilities that the political climate will endorse and support the plan. While social planning has numerous objectives; planning with respect to decision making may be understood as falling under the following conceptions:

1. Social planning seeks to clearly identify the problems, resources and means for application of these resources to the problem. For decision 
makers this involves the specification of the various alternatives available for the definition and solution of a problem.

2. Social planning should establish a clear set of priorities within and between any set of policy alternatives. This means that the planning exercise needs to provide the decision maker with a clear picture of the logical requisites for the implementation of a plan (e.g., a PERT or similar statement with respect to the alternatives being considered.)

3. Social planners need to be aware of the effects of operations in one area or on one set of problems upon other areas of the social network. 'I'he decision maker needs to realize that his actions with respect toward any given alternative will have wider effects than are usually specified in the proposal before him/her.

4. Finally, social planners need to be aware of the limitations of intervention. The decision maker often finds himself the agent of imposing such limitations--e.g., budget constraints, political constraints, etc.--to a proposed course of action. 
If we accept these four objectives for social planning in relation to the decision making process, certain basic problems that form a cluster around the decision making process emerge as important to the decision process. These problems have often been ignored in the analysis of decision making in social service agencies (Neghandi, 1975:1-15). It is in reference to these problems that the model of the decision process was designed.

We may note some of these problems directly; others will emerge as the model is applied to the analysis of the decision process. Specifically, an examination of the planning and decision literature as well as field experience in social agencies shows that:

1. Planners often propose courses of action without reference to the Iimitations, effects of implementation on other areas, or alternative courses of action.

and

2. Decision makers, usually a different body than the planning body, tend only to stress the limitations of implementation for a plan-these being their primary area of responsibility.

Illustrations of these points may be found in the work of Piven and Cloward (1971). In this work the authors blame the politicians for not accepting their planning efforts. However, it is not the task of planners to set policy, but to develop means to implement 
policy. (Bolan and Nutall, 1975) Policy is formed at the political level of social organization (Weber, 1946). Piven and Cloward should have been aware of political perceptions and planned accordingly. If they had taken into account the political climate of the time and "packaged" their proposals in a manner that would have made them more acceptable to the political decision maker they would have been in a much stronger position to achieve their ends.

In many case ideological factors tend to mask limitations from planners. Mannheim (1936) noted the tendency of problem perception to vary with social classes and socio-economic conditions. In a more recent example Arnstein (1969) is illustrative of the manner whereby her Marxian assumptions mask her analysis from the realities of the political decision making process. Ideological approaches tend to seek to fix blame rather than to solve the problem.

Of course decision makers are equally subject to all of these ideological and structural role situations as well. However, it is the planners task to uncover these instances of limited perspective and to clarify the alternatives before the decision maker rather than the opposite.

In actual practice planners are usually found in administrative agencies, and the fiscal controls that determine the scope and type of service to be provided lies in some political body that is responsible to the public at large-city or county councils, state legislatures or the national Congress. 
In such situations where responsibility is divided from authority there tends to be a narrowness in planning exercises, and the proposed courses of action are conceptualized in fundamentally different ways by planners and decision makers. Much the same situation exists in the relationship of planners and the staff of an agency in that the staff needs to respond to the immediate needs of a client population whereas planners concern themselves with the future of society. In each case there are, again, fundamental differences in assumptions.

Traditional approaches to decision making tend to stress that these differences in frame of reference are due to the structural characteristics of an agency; especially its hierarchial stratification (Weber, 1946). Such approaches are based on one of several schools of thought, all of which contain anomalies. If the theoretical structure for traditional approaches to differences in perception of problems is lacking, it follows that the decision models generated from such theoretical models are equally suspect. The model presented in Chapter II seeks to avoid some of the anomalies in the theoretical approaches that underlie traditional decision making models. However, a review of the anomalies of the traditional schools of thought is in order and follows directly.

\section{Review of Traditional Theories}

Decision making has been the subject of numerous studies; indeed the literature is enormous. This large body of material may 
be grouped and considered parsimoniously by defining a various "schools". In this review the critique will be limited to an examination of the fundamental tenants of these schools, since it is in these assumptive bases of the theories that the anomalies may be found.

It is possible to identify three such "schools of thought" with reference to the problem of decision making in a social context. Briefly these are: value theory, conflict theory and the structurefunctional approach. Each will be discussed in turn.

\section{a. Value Theory}

Decision making from the perview of value of theory maintains that decisions spring from basic values, and that the priorities that are exhibited in a decision matrix are isomorphic to the values of the decision maker or decision system. Thus Braybrooke and Lindbloom (1963) maintains that policy decisions reflect or change in response to values. "The felicific calculus....presumes that the unity of action (or policy) can be reduced to the value of pleasure or pain" (Braybrooke and Lindbloom, 1963:214). Changes in decisions are thus seen to be reflections of changes in values, and attempts to effectively intervene in the social process by a social values of the groups concemed or deal with the problem of changing values. Planning efforts that 
are based upon value theory thus emphasize the need to change values (Medina and Reyes, 1976, pp. 515-517). While values are certainly reflected in decisions, changes in decision seldom if ever reflect changes in values. Abundent evidence from psychology (Kohler, 1947), anthropology (Redfield, 1946, 1956a, 1956b; Singer, 1972) and sociology (Warner, 1958) show that values change very slowly, and that value changes involve changes in basic social structures that persist through time. However, political decisions necessarily are short run in character and only reflect values in a very general sense. Therefore, value theory, by its very nature is unsuited to the analysis of decision making, especially in political context as represented by an agency. More importantly, the term value has no real operational definition (Morris, 1956), and assertions that value changes have occurred have not been demonstrated in anything but the most general descriptive manner.

In general then, value theory as far as political decision making is concerned, is of interest only in terms of eliciting long term historical trends, and these have only tenuous scientific value. The theoretical school based upon values thus appears to have 
no signifioance for the analysis of decision making within the limits of this study. b. Conflict Theory

Decision making implies that a choice is required between alternatives, so it follows that conflict situations are potentially part of any decision making process. Conflict theory seeks to provide a theoretical matrix whereby conflict-and by implication decision making may be understood.

All conflict theories maintain that resources are limited. There are however, at least two different ways in which varieties of conflict theory suggest in dealing with this postulate (Dahrendorf, 1967:206) (Coser, 1956:17). One variety maintains that resources, being limited, must be disproportionately allocated to create a sufficient basis for capital formation to permit social programs to be developed. This disproportionate allocation leads to the development of control mechanisms (e.g., bureaucracy) which in turn tend to become introverted and self protective to the extent that the surplus produced from the initial concentration of resources for capitalization is used to maintain the group with the power derived from such allocations to retain its privileged position (Coser, 1967:77). The resultant 
neglect of the other groups who do not have as large a share of the resources may in the minds of some conflict theorists lead to revolution (Marx, 1932) or to some form of elite circulation (Pareto, 1966; Aron, $1968,1970)$

The other major branch of conflict theory sees the essential problem as being the same-the disproportionate allocation of resources, but feels that the instruments of government may be used to redistribute the surplus produced from such capitalization. They do not necessarily seek to redistribute the basis of capital formation, but they do seek to equalize the distribution of the eamings. Such a redistribution can, it is asserted, make for a more democratic form of control of the power base, since power is seen as deriving from the use of the surplus of the capital concentration. In many cases the practitioners of such a point of view use social planning to assure the redistribution of the surplus. The Beverage Plan for Public Welfare in the late 1940's was such a plan (Crossland, 1956). Examples of this approach as applied in the United States can be found in the cases reported in Marris and Rein (1969). Decision making with respect to conflict theory in the context of a description of conflict itself 
tends to focus on such areas as labor-management relations (Lipset, 1956), community relations (Alinski, 1967) political sociology (Coser, 1961), etc. The limitation of all these types of conflict analysis for decision making analysis is that the materials presented are by and large post hoc case studies, and that the results tend to be case specific with little or no predictive value.

The basic tenents of conflict theory is that they are untested assertions, and while interesting in that the theories can account for change they do so in a manner that is not amenable to empirical testing. More importantly, conflict is studied in terms of itself; that is, conflict is seen in a tauntological manner where certain situations are seen as creating conflict, and conflict is seen as creating these situations (Arnstein, 1977). c. Structure-Functionalism

The structural functionsl theoretical matrix has dominated social analysis for the last twenty years or more (Martindale, 1960). Most of the theories of planning and decision making used in social work are reflections of this approach and consequently suffer from the limitations that characterize it (Kahn, 1969; Bolan and Nuttal1, 1975; Warren, 196708). 
The basic tenents of structural functional. approaches are conventently summarized by Merton (1968) and may be expressed as a series of propositions,

1. Soclety consists of a series of elements that are combined into co-ordinated, functioning whole.

2. These elements are relatively persistent and tend toward equilibrium.

3. All elements within the social structure interact with all other elements; change is essentially a disruption of equilibrium and so is dysfunctional.

4. The elements of society are derived from needs, and the structure functions to satisfy these needs.

Structure-functional approaches thus are essentially statis in conceptualization; it has no way to really consider change (Levi, 1968; Damerath and Peterson, 1967). The analytical basis of structurefunctionalism is the maintenance of the configurationthat is system maintenance (Radcliffe-Brown, 1957; Nadel, 1958). Any change in the configurations elements that does not maintain the same basic relationships between the parts of the system is necessarily a new structural entity. But the conceptual base of the 
structure-functional approach has no theoretical means to account for the emergence of a new configuration; it only permits hypotheses to be formed about why structures maintain their structural properties (Levi, 1968). In addition, the grounds to the theory lie in the assertion of universal needs (Malinowski, 1922). This is an untested and untestable proposition, since there is empirical case where the absence of a universal is possible. In effect the theoretical applications of structure-functional theory have all been post hoc case studies. There are no studies that predict the behaviors of a system in any replicable manner (Warren, 1967). Decision making within a structural-functional matrix thus is based upon the attempt to maintain the structural integrity of the boundary of the on-going system as well as its functional unity. The concept of needs satisfaction (Malinowski, 1922)-and the assumption of the dysfunctional effect of needs deprivation-leads to decisions that are governed by the requisites to provide such satisfactions. 'The emphasis on goals formulated on a universal assertion makes the decision process an exercise in tautology: needs create dysfunctions, these dismpt the system so decisions are needed to satisfy needs, but since all needs are ultimately universal, the apparent 
decision to satiafy them is only a functional outcome of the structure that expresses these needs. Thus since needs deprivations exist, they must satisfy a function-and their satisfaction will thus be dysfunctional.

\section{Comparative Analysis}

While all of the theoretical approaches listed above have specific differences they all share certain factors that have a tendency to obscure the decision making process. We may note the following as a set of common failings for the traditional approaches to the analygis of decision making:

1. All of the theories reviewed tend to be subject natter specific, that is they tend to consider decision making as a subprocess of some larger process. This larger process is characterized by the categorization of the phenomena along Iines that sees the subject matter of inquiry as determining the analytical procedure whereby such a subject is studied. Thus political decisions are anslysed according to the percepts of political science; those involving social institutions by sociological percepts, etc. There is no common framework of analysis when materials are conceptualized within subject matter limitations (McKeon, 1954). 
2. There is a tendency to see processes that are the basis of theory at the same level as analysis as that of theory itself. (e.g., relationships between institutions are expressed in terms of the institutions themselves.) This violation if the theory of Logical Types tends to produce tautology and paradox in any attempt to formalize the findings (Bateson, 1972).

3. All of the approaches considered tend to produce without establishing a means by which these assumptions may be empirically tested. Where empirical work does exist its range is usually limited to a set of conditions that makes 1ts theoretical extension very difficult if not impossible.

4. None of the social planning efforts that have been formulated on the basis of these theories has shown any success in predicting policy outcomes. In general, this failure in application tends to stem from the fact that almost all of the theories considered above are static in nature, that is they do not make provision for change within the matrix of analysis (Neghandi, 1976). 
5. Finally, those policy formulations that have been made utilizing these theoretical approaches have for the most part proved to be nonquantifiable in nature so that replication and validation proves to be impossible.

This review of the literature has shown that the current theoretical orientations that underlie most decision analysis are limited and really incapable of dealing with the decision making process. Static, subject matter based approaches cannot deal with change over time, but decision processes, at least in policy areas, require this dynamic ability on the part of a theoretical framework for decision analysis. Change is, after the primary context of policy.

When we examine the objections to the traditional approaches we see that change is conceptualized in all three as occurring within the boundaries of the schemata of analysis; that is, these traditional approaches exhibit the characteristics of a closed system. This closure tends to stem from the subject matter definitions that delineate a problem. In such approaches methodology is seen as a function of the subject matter, where elements of analysis are derived from the definition of the problem which is in turn derived from a discipline. For example, sociology has as its subject matter ideas of groups, classes, etc. The sociologist thus tends to see all social dynamics as being the result of the behavior of groups. But the emphasis throughout will be on the characteristics of the groups-not on their interaction (Warner, 1958; Bendix and Lipset, 1966). 
Such parochialism is not the fault of soclology alone, all subject matter defined disciplines operate in a similar manner. In the analysis of decision making the problem is to focus on change itself; not on what changes.

A new approach is thus called for and should have certain features in its makeup that will avoid the problems and anomalies we have noted for traditional theory. Among these criteria are the following:

1. The approach must be dynamic; it must assume that change is the primary feature in decision making.

2. The approach must be nonsubstantive so that the relationships between phenomena are considered rather than the character of the phenomena (e.g., subject matter) itself.

3. The data collected must be scientific in character that is: quantifiable, replicable and testable. The model used must produce hypotheses that will permit the testing and verification of results.

\section{The Systems Approach}

The area of systems analysis has, or seeks to supply, tools for the construction of models that meet the criteria noted above. Accordingly a number of systems approaches have been utilized in the 
construction of a model for the analysis of decision making.

In general, systems approaches offer a different perspective than is the case with traditional approaches.

1. Systems approaches are not subject matter specific.

Thus a systems approach to change would see change as a basic process that cuts across all disciplines and is not a function of any particular entity changing. Thus, social groups are entities that change, but so are personalities or economic structures. The common element to all is that they all are aspects of change per se. A systems approach, being non subject matter oriented, can deal with such problems that transcend subject matter defined disciplines. (Buckley, 1968; Klir, 1969; Bateson, 1972)

2. Systems approaches are capable of dealing with inputs that have their sources outside of the boundaries that define a system (i.e., open systems). They can consider such things as innovations or unexpected changes prior to their occurrence so that the system can be made capable of taking in such occurrences without needing to redefine the whole system. 
Systems analytical approaches can deal equally

well with colsed systems and so the possibility

of a single frame of reference for decision

analysis is theoretically possible (von Bertlanffy, 1972).

When a systems perspective is utilized in the consideration of social problems, the four basic criteria for effective social planning and decision making previously described come into the realm of possibility.

More importantly, a systems perspective to social problems allows us to see the key role played by decision making within the whole social service field. Planning from a systems point of view sees decision making as central because planning requires that goals be reached with limited resources and also recognizes that goals are sometimes contradictory or shift radically (i.e., from planning time to time of implementation(Bolan and Nuttall, 1975). Since planning without implementation is useless, decision making becomes central in the allocation of resources and the establishment of priorities.

This key role for decision making in the systems approach is in clear contradistinction to the traditional approaches where decision making is understood as a function of the group making the decision (as in sociology) individual evaluation of the problems involved in decision (as in psychology) or of the power of an office (as in political science). 
The systems approach to decision making finds the nexus of the decision process in the areas of boundary intersection between subsystems or systems where the character and coding of inputs and outputs are different (Bateson, 1972; Rapaport, 1974; Flannery, 1971). The noture of these differences and the consequences of their mutual interaction are the basis of the modeling exercise in Chapter II. 


\section{CHAPTER II}

A MODEL OF THE DECISION PROCESS IN SOCIAL AGENCIES

As wo have noted a systems approach to the decision making process involveg the analysis of the various subsystems that compose the empirical situation. In this case the empirical situation with which we are concerned is the reorganization of the State of Oregon, Department of Human Resources as it relates to Elderly Programs. The actual observations that have been made have been abstracted so that the model will not be case specific, but rather serve as a vehicle to generate hypotheses about decision making processes in other situations where reorganization of units affects the operations of those units.

The perticular subsystems, once identified, can then be considered in terms of their systemic characteristics-apecifically the nature of the coding of the input-output exchanges that exist between them, and the consequences of these exchanges throught the whole sybtem (e.g., services for the elderly before and after reorganization).

\section{Elements of a Decision Process}

Both fleld observation and a large body of literature in the area of the organization of social service agencies (Gilbert and Specht, 1974; Trattner, 1974), may be reduced to a set of elements or subsystems that make up the administrative system (Simon, 1968). 
We can identify three besic subsystems, two of which have structural charaoteristics of their own.

1. There is a political subsystem. This element is the locus of fiscal authority. In many cases it may be divided into two subsystems: a political legislative function and a fiscal accounting subsystem. In the case of the State of Oregon these two latter functional subsystems are represented by Legislative Fiscal and Legislative Review.

2. There is a bureaucratic subsystem which is the locus of the administrative system's operations. This subsystem is also charscterized by dual functions: a managerial function and a service delivery function. The bureaucratic subsystem in the case of Oregon is the Department of Human Resources.

3. There is a public subsystem. This public subsyotem is involved with the political subsystem through its voting function while it is involved with the bureaucracy through its client function.

Clearly not all of the public is always involved with a service delivery system; indeed there are clients who are not voters, voters who are not clients, etc. However, the public is of importance in 
modeling decision operations in government agencies because it is they who both determine and receive the throughputs of the whole system. In this model therefore, the public is included with respect to how its systemic characteristics function when it does interface with a human services system and thus influences the operations of tha system.

The three subsystems identified above interface with each other In a manner described in Figure 1. The ensuing structural relations create a series of intersections. It is upon these intersections that a systems approach focuses. Examination of the figure reveals that there are three basic interfaces:

1. The Political-Bureaucratic Interface. This interface is mediated by the political aspect of the political subsystem and the managerial aspect of the bureaucratic subsystem.

2. The Bureaucratic-Public Interface. This interface is mediated by the service delivery aspect of the bureaucratic subsystem and by the client aspect of the public subsystem.

3. The Political-Public Interface. This interface is mediated by the representationallegislative aspect of the political subsystem and the voter aspect of the public subsystem. 
FIGURE 1

SYSTEMIC REIATIONSHIPS OF THREE ELEMENTS

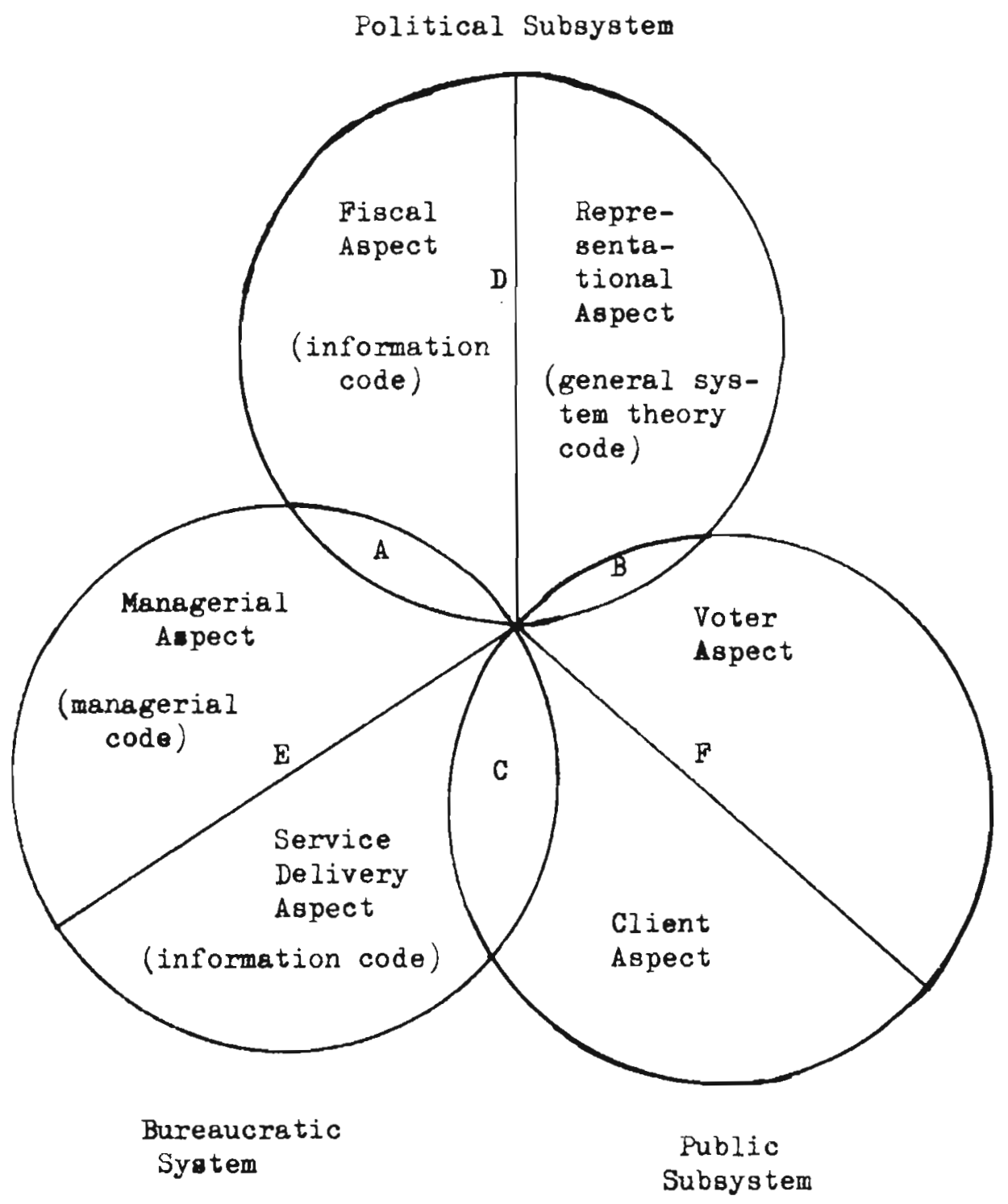

A, B, C = Interfaces between Subsystem

D, E, $F=$ Interfaces within Subsystem 
2. The Dynamica of Interface within the System

The operations that take place between subsystems that interface with one another exhibit geveral characteristics that permit the analysis of the dynamics of their interaction across system boundaries. Four basio features have been identified in systems literature as obtaining in such cases. These features are as follows

1. The mechanisms of input reception; that is, what kinds of inputs are received by the subsystem and what kinds are filtered out? (Weaver, 1964).

2. The output generating mechanism; i.e., what kinds of outputs is the subsystem capable of generating? (Weiner, 1954; Ashby, 1956, 1962)

3. The coding operations of the subsystem; i.e., the means by which inputs and outputs are created by the subsystem. (Bateson, 1972)

4. The general character of the subsystem's feedback structure with respect to its ability to adapt to change. (Bateson, 1972; Ashby, 1956)

These aspects may be examined in greater detail. a. Mechanisms for Input Reception Input receptivity of a system is a function of its openness. Systems may be classified into two types: open systems that can accept inputs from sources located outside 
of the systems boundary, and closed systems, or those that can only deal with inputs that have their sources within the boundary of the system (Ashby, 1956). As has been noted above in Chapter I, closed systems tend to exhibit certain limiting behaviors-the inputs from outside of the system's boundary is either not received at all, having been filtered out by the conoeptual or empirical boundary maintaining procedures of the systems, or the input is from outside of the system are understood to signify a danger to system stability and reactions to exogeneous inputs are treated in an antagonistic manner (Weiner, 1954; Weaver, 1964; Rapaport, 1960. Mechanisms that are capable of accepting exogeneous inputs are for the most part systems that have been designed to change rather than maintain themselves (Mayr, 1970; Bateson, 1972). In closed systems, the system is defined by the boundary. System processes thus seek to maintain the system and preserve the boundary and filter out any inputs that violate the boundary. As noted in Chapter I, this is the situation that occurs in those intellectual disciplines that see subject matter boundaries as the basis of analyais. In an open system, the system is understood as fulfilling a certain operational task (Fried and Molnar, 1975) and as long as that task is performed, the boundary is extraneous to the analysis. 
Subsystems, or functional aspects of subsystems, that exhibit closed input reception mechanisms or behaviors tend to be concerned with the maintenance of structural characteriatics rather than with the performance of a task for which the structure was designed. Bureaucracy is of course, the classic example of this phenomena (Weber, 1946; Bendix, 1963; Merton, 1957). Open systems, where operational performance is of primary concern, tend to ignore the structural characteristics of the setting for their action. (Kast and Rosenzweig, 1972; Fried and Molnar, 1975)

\section{b. Output Generating Mechanism}

Much of what has been stated previously applies to this facet of the operations that occur in an interface. However, it is important to note that the functions of input and of output are different and distinct. Input does not necessarily govern output or vice versa. Thus in the service delivery-client interface, the agent dispensing services is generally faced with a multitude of inputs, many of which are extraneous to his closed system definition of service delivery. The client is thus forced to either accommodate himself to the closed system needs of the bureaucracy, or of not receiving services. In similar fashion, bureaucratic output to the public is in the form of a closed system-regulations, forms, etc., which may or may not fit the relatively unstructured open system of a 
client's life but does not obviate the client's needs.

Situations where outputs are similar to each other, as in the public/voter-political/representative interface tend to show a clear, usually smooth functioning pattern despite its unstructured-and from a closed systems point of view chaotic-features. (Bendix and Lipset, 1966)

c. Coding Operatings of the Subsygtem

While not all systems are involved in the transfer of information over an interface, information flow is characteristic of any human services system. In the case of the model being developed here, information flow is the basis of the input-output operations. In order for information to have a reality it must be coded; that is, it must have a vehicle to effects its transfer (Weaver, 1964; Ashby, 1956). In most systems that vehicle is a species of a language or symbol system that is capable of transferring a meaningful message (Ashby, 1954).

Language differ in coding, that is in the symbols utilized or in patterns of message interpretation as carried by these symbols. The model assumes that the participants involved all use the same set of basic symbolsthat is verbal and written language. There is abundant evidence to show that the various subsystems involved in a human services agency utilize different patterns of the contents of a message. The whole legal-administrative 
institutional structure is a mirror to the various possible interpretations that may ensue from an exchange over an interface.

The basic hypothesis of this research is that language differences-understood here to mean differences in the patterns of interpretation of message contents-vary directly with the characteristics of the input-output mechanisms involved in information exchange. This is to say that a subsystem that generates outputs that are open is tuilizing a different language interpretation package (code) than is a subsystem that generates closed inputs. We shall deal with the differences and empirical characteristics of different codes or "languages" in Chapter III. It is these differing coding procedures that gives the model's predictions, the potential for empirical testing and verification.

d. Characteristics of the Subsystem with Respect to Change This aspect of the interface relationships refers to the ability of the totel system, in this case all three subsystems acting in concert, to either maintain or change its functions. Most human services systems tend to have the anomalies between subsystems that have been noted in the table above; that is, there is an attempt to tie together open and closed subsystems within a single unit. Most systems that have a unity of coding exchanges amongst 
SUMMARY OF INTERACTION PATTERNS IN THE SYSTEMIC RELATIONSHIP BETWEEN SUBSYSTEMS

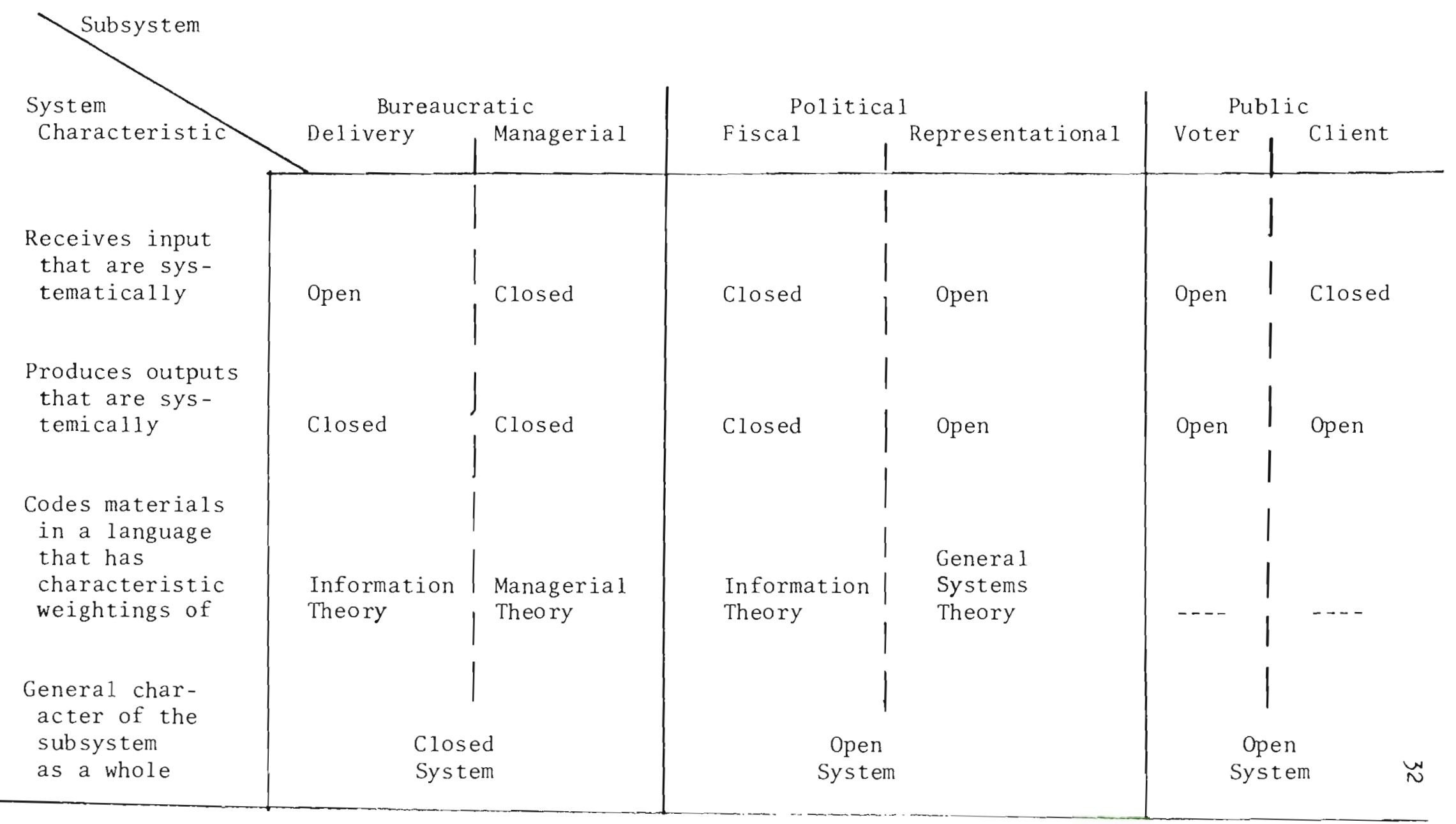


their subsystemg tend to be stable; although institutionally these have almost always been of the closed system variety. Thus, in primitive societies the political, kinship, residence and inheritance patterns all tend to have the same coding patterm. (Murdock, 1954; Eisenstadt, 1966, 1968) Indeed, culture contact is seen as occurring where mixed codings oocur (as for example amongst the Yapese where kin types are mixed but political authority is not (Lingenfelter, 1975).

Systems that have mixed codings for their subsystems have a potential to change, or adapt to change whereas those that have all of their codes of a closed variety tend to be mortibund in the face of change. Empirical examples of systems with all of the subsystems exhibiting open coding procedures are lacking, at least to our knowledge. The character of the coding exchanges between subsystems thus has a direct impact upon the ability of the total system to adapt to new circumstances and conditions.

\section{Limits to Model Testing}

In formulating the model and deriving hypotheses from it, it was necessary to restrict the latter to hypotheses concerning the interfaces of the bureaucratic and political subsystems and their functional aspects. These two elements are potentially testable in that they possess much more clearly defined boundaries than does the 
public element; the public being heterogeneous with the respect to culture, values, classes, etc. Constraints of time and funding make the analysis of the public interfaces impossible within the context of this research. However, the model is able to generate hypotheses that Include the public as a factor and these may be tested at a later time.

\section{Hypotheses Generated by the Model}

The function of any model is to provide a synoptic understanding of the phenomena being examined so that hypotheses about the phenomena may be formulated in a manner that permits empirical testing and the validation of the theoretical basis of the model (Popper, 1972). The theoretical basis of this model is that of a systems approach. Such an approach maintains that the significant operations within or between systems occur at the boundaries of the systems or their attendant subsystem (Flannery, 1971). The approach has also established certain conceptions as to the form wherein these boundary interactions take place-input-output; open and closed features; and coding differences.

With respect to these three variables we may formulate the following hypotheses:

1. An interface where inputs from one system are coded in the same manner and share either openness or closedness as those of another subsystem will exhibit greater information flow; produce greater 
amounts of effective behavior in its appointed tasks with respect to the subsystem being interfaced; and exhibit generally greater cost-beneficial behavior.

2. An interface that exhibits different coding or openclosed features will produce less information flow; exhibit less effective behavior in accomplishing appointed tasks with respect to the subsystems being interfaced, and will exhibit a poor cost-beneficial behavior.

3. Interfaces where there are similar patterns of output, either in coding or openness or closedness will exhibit greater information flow, produce greater amounts of effective intersystems behavior in appointed tasks, and prove to be cost effective.

4. Interfaces with different patterns of output, either in coding or their open/closed character, will exhibit less information flow; produce lesser amouts of effective intergystems behavior in appointed tasks, and prove to be non cost effective.

These hypotheses will be formulated more specifically into predictions about "language" utilization in the next chapter. The languages or codes whereby information flows from one subsystem to another are specified in Chapter III. An instrument to permit the content analysis of proposed legislation and testimony as well as 
operational documentation of the internal administrative agency concerning the proposed reorganization of the Oregon State DHR will then be formulated. The results of the analysis will then form the basis of prediction as to outcomes in the reorganization effort. 
CHAPTER III

AN ANALYSIS OF THREE BASIC SYSTEMS CODES

A has been pointed out previously the model generates three different coding procedures or "languages" of interpretation; each of which characterizes a different interface between subsystems of the model. This chapter seeks to formulate a paradigm that will permit the different features of each code to be specific so that an ingtrument based upon these differences can be constructed and various forms of evidence-documents, testimony, etc., can be considered and adjudged to represent one of the codes. Once a coding type can be assigned to a representative document or item, and its origin is located in the model, then the hypotheses about the efficacy of a particular code to bridge an interface may be predicted. This chapter will determine the three basic coding frames of reference for three fundamental systems approaches: General Systems Theory; Information Theory and Managerial Theory. These three forms of problem definition and decision making were selected both because these theoretical constructs are appropriate to the model but because they also constitute the primary varieties of systems approaches used in social analysis (Buckley, 1964).

\section{A. A Paradigm for the Analysis of Theoretical Construct}

The analysis of any theoretical construct is difficult, and there are several possible approaches (Boas, 1969; Lovejoy, 1936). 
However, since this research is concerned with the logical structure and the particular terminological devices that are characteristic of various theoretical points of view, it is possible to utilize a modifield version of a paradigm developed by Richard McKeon (1954), which focuses on these elements as against historical developments of ideas.

The McKeon paradigm reduces to several fundamental questions that may be addressed to any intellectual construct. The four basic aspects with which this research will be concerned are:

1. The specific problem that the theoretical construct is designed to address.

2. The basic assumptions that underlie the particular approach.

3. The methodology of the approach; that is the specific means by which the assumptions are applied to the problem.

4. The data categories that are appropriate to test the adequate of the theory and method of application to the problem.

Clearly all theoretical constructs involve the definition of a set of boundaries that delineate a problem-a "problem space". As the specification of the parameters of the problem becomes more exact, the problem itself comes into clearer focus. In most instances the definition of the problem space parameters involves underlying assumptions that also condition the theoretical approach 
to that problem. It is also true that when new problems and theoretical assumptions are advanced, many of the older problem spaces are aubsumed into the new construct or disappear altogether. Thus, for example, the concepts of space in Newtonian physics are now subsumed into the theoretical constructs of Einsteinian space, and appear there as a special case. (Max Jammer, 1962; Cassirer, 1953) In siaflar fashion, many of the problems that appear and condition the theoretical constructs of Social Work derive from an individualistic assumptive set-based on clinical approaches. In a systems approach the problem space is statistical in nature, not case specific, and so involves a different set of assumptions than are the norm in much of the social work literature.

In each of the detailed analyses that are presented below the configuration of the problem space will provide one of the key dimensions of the analysis into the logical structure and meaning for the terms that the paradigm seeks to identify.

The basic assumptions that underlie a particular approach-its "theory" not only determine the problem space but also the character of the "solution-space" that will govern the organization of the manner whereby the problem is to be solved.

The methodological aspect of the paradigm seeks to identify the specific means whereby the solution space is matched to the problem space in a manner that permits the testing of the resulting hypothesea. Finally, data categories refer to the criteria whereby empirical materials become instruments for testing the hypotheses 
provided by the methodological exeroise.

These four aspects of an intellectual construct, when used in a comparative manner permit the explication of the logical structure and identification of fundamental terms within any given construct. These relationships form the basis for the tables and discussions that follow. Each table seeks to provide in convient form a comparative synopsis of the intellectual constructs of three representative thinkers who are especially concerned with the particular theoretical form that is the basis of analysis. The discussions that follow both describe in expositional and comparative manner the conceptual framework of each author. Finally, each section will seek to find the basic, common underlying principles that are features for all of the authors. We will use these commonalities as the basis for delineating the code for that approach-that is the "language" for each frame of reference-General Systems Theory; Information Theory and Managerial Theory.

B. Application of the Paradigm to General Systems Theory

General Systems Theory (GST) is a collective term that is used to describe those theoretical approaches that seek to characterize and understand the behavior of aystem per se. (von Bertlanffy, 1962) This is to say it seeks to comprehend the relationships that obtain between systems, of any type, when they function as systems. In performing such analyses three basic problems emerge from the operations of a system: Change, conflict and gystem maintenance. 
Change is a focus for the work of Gregory Bateson, and is involved in the operations of almost all systems approaches since dynamics are characteristic of problems to which systems analysis is addressed. Conflict is a fundamental form of social dynamics (Martindale, 1960; Sorokin, 1963; Bames, 1952) and the systems approaches of Rapaport have their locus in this problem. Finally, the problem of essential system process maintenance is the focal point of the works of von Bertlanfy.

There are, of course, other problems with which systems analysts are concerned, but these three points appear to form a nexus in the literature when General Systems Theory is concemedespecially with respect to problems of a social and cultural nature.

1. The Problem of Change and System Dynamica:

Gregory Bateson

Bateson is unusual in systems analysig in that he not only is an important figure in General

Systems Theory, but has applied the concepts of systems analysis to a wide variety of materials, from many disciplines-anthropology, psychology, zoology-as well as political science and ecology. In his various publications, 1951, 1952, 1972; Bateson focuses throughout on the problem of change; change both within a system and from one system into another as occurs in evolutionary processes. 
COMPARATIVE CHART OF THE PARADIGMATIC ANALYSiS OF THE GENERAL SYSTEMS THEORY AUTHORS

$\begin{array}{lll}\text { Author } & \text { Basic Problem } & \text { Theory } \\ & & \\ & \text { Change is not } \\ & \text { specific to a sub- } \\ & \text { ject matter; it } \\ & \text { can be considered } \\ & \text { in terms of infor- } \\ & \text { mation. This is an } \\ & \text { information model. }\end{array}$

A. Rapaport Conflict

This is a mathemat -

\section{Method}

Define information character as being coded, redundant and exhibiting feedback. Structure is guaranteed by the Theory of Types . ical model and so 1. is not subject matter specific; 2. exhibits rigorous deduction of hypotheses; 3 . produces a testable situation.

There are three steps in the procedure: Formulation of a model; deduction of hypotheses; experimental verification of rejection of the hypothesis.

Mathematical models permit the comparative analysis of
Data

Cultural, Biological and Psychological materials. two different areas-games and debates.

Similar form - similar process. Differences in substantive operations are not important.
Mathematical treatment of games and debates. 
TABLE III-I

(continued)

Author

L.

von Bertlanffy
Basic Problem

Sys tem

Maintenance
Theory

This is a biolog-

ical model. Sys-

tems are main-

tained by hom-

stasis. Change is

a homostatic

process.
Method

Locate corresponding abstractions in various model of disciplines.

Build a mathematical model of these abstractions.

Models are cybernetic in nature; either open or closed feedback loops exist. In organisms there is both change and maintenance.
Data

Living

Systems;

Biological

Systems. 
While Bateson conceptualizes change as a problem of information transfer, he adds a criterion of the maintenance of level of analysis for the conceptualization of change that makes this theory a species of General Systems Theory rather than information theory alone. Systems for Bateson all possess certain relationships in common, whatever their empirical basis. Firstly, all systems exhibit cybernetic feedback as a means of preserving system boundary. However, the nature of the feedback mechanism is more complex in Bateson's analysis than in many theoretical formulations. Feedback is not only positive or negative (system changing or maintaining) but occurs between levels of analysis as well. Levels of analysis is Bateson's adoption of Russel and Whitehead's Theory of Logical Types. The theory of types states briefly that to avoid paradox, a member of a class of objects cannot define itself. For example, a thing cannot be same thing as its name (Bateson, 1972:280). In his work with Reusch on Communications (1951), Bateson identifies at least four levels of meaning 
within every transfer of information; and feedback is such a form of information transfer.

These considerations modify the other information processes used by Bateson in his theory as well. Coding, another general systems process also exhibits levels. Confusion between codes is often found empirically in such phenomena as schizophrenia (Bateson, 1972:201), especially in the phenomena of the "double bind" (Bateson, 1972:271). Closely connected with the concept of coding is that of redundancy-the process by which coded messages are made meaningful. This latter serves as the basis for cognition; only redundancy permits patterns to be leamed through repetition. Traditional stimulusresponse learning theory for example in Batesonian systems becomes a matter of feedback and redundancy. However, the systems formulation of the concept is wider and can be identified as a process in various contexts, not just of a description of a particular stimulus/response activity around a particular object by a particular animal. 
It thus has greater power and greater value as

a scientific conceptualization.

Bateson utilizes these four concepts, feedback, coding, redundancy and level of an-

alysis to consider change throughout a spectrum of phenomena.

He begins with an analysis of genetic change in evolution, moves through mammalian animal communications to linguistic and symbol systems of individuals and whole cultures. Each of the stages in his presentation is at a different level of organization and analysis and each exhibits learning and information trangfer both within and between levels. The four elements of his conception of General Systems Theory thus permit Bateson to develop a comprehensive theoretical picture of change; describe its processes in terms of feedback and learning, and evolution through time in both evolutionary and symbolic dimensions. Applying the paradigm directly then to Bateson's concepts we can easily define the locus of his efforts; his problem as change. On the theoretical level change is seen to occur in all phenomena; it is the basic 
relationship that exists in the universe of discourse for science. Change in this relational mode is best seen in a non specific manner, and this is furnished by the concept of information. Methodologically, Bateson treats the informational characteristics of change with four primary conceptual tools: feedback, coding, redundancy and guarantees the resultant structures logically with the Theory of Types. The data base is very widegenetics, biological evolution, linguistic and socio-cultural materials are all interpreted within this single frame of reference provided by Bateson in his formulation of the problem of change.

\section{The Problem of Conflict in Systems:}

Anatole Rapaport

The second locus of systemic process that provide a formulation for a general systems approach is the phenomena of conflict. While change is perhaps universal, conflict appears in most processes of change, if not all of them. Certainly many political, economio and sociological conceptions depend on conflict (Marx, 1932; Hofstadter, 1952; 
Dahrendorf, 1967; etc.); and even those that postulate a non-conflicting basis for human interactions such as structure functionalists (Parsons, 1951; Parsons and Shils, 1956; etc.) accept the fact that conflict does occur, even as a sort of functional dysfunction (Coser, 1956). Conflict then has a wide enough base in human affairs to warrant a treatment in general systems terms. Rapaport seeks to provide a general systems theory for human behavior based upon the analysis of conflict. His approach is through the application of various mathematical model so instances of conflict in human affairs. Basically he classifies them into situations of fights, where conflict tends toward annihilation of the opponent; games where strategic thought is applied within a set of accepted rules, and finally into debates where conflict is formalized so that it is highly controlled and resolution of the conflict is symbolic. These observations are found in his 1960 works Fight Fames and Debates. Later extensions of the theory from ideal types to historical instances analysed along the mathematical lines 
suggested in this volume have appeared in the volume on Conflict (1974).

The mathematical approach that is advocated by Rapaport has basic characteristics that is of import to a general systems approach. Clearly mathematics is a relational logic; its operations and conclusions are based upon sets of axioms and definitions of process that have no connection with any particularity of an object or event that it treats. Mathematics thus is a non subject matter specific discipline par excellence. In addition mathematical approaches provide a means by which rigorous deductions of hypotheses may be made. This is perhaps the most important aspect of this instrumentality; its formal logical structure that permits clear and unambiguous (at least relatively) definition of circumstances that is beyond another linguistic tool we possess. Finally, a mathematical approach provides the careful theoretician with a means to furnish testable hypotheses. These latter are possible because of the logical structure of the operational definition becomes formalized in the 
application of mathematical processes.

Methodologically, the mathematical

approach permits the comparative analysis of what appear to be very different empirical

behaviors by discovering similarities between them when they can both find their behaviors predicted from a common set of definitions and hypotheses. Thus, games and debates, while empirically different, are shown in Rapaport's work to have the same underlying structure; indeed, therefore, to be the same thing. Thus, the variety of behaviors that one finds empirically can begin to attain some theoretical basis. Forms of conflict ranging from a formal parliamentary discussion to a football game to operations of the stock market to the formulation of war plans by defense agencies all are seen to be capable of being comprehended and understood within a single theoretical matrix. The accomplishment of this theoretical unification is the aim of science in general and general systems theory in particular. The data base from which Rapaport works is essentially a set of mathematical 
formulations that have the status of well

formed theories: these constitute the Theory

of Games. This, and empirical examples of conflict are united in his approach to conflict to provide a general systems formulation of human behavior.

3. The System as a Whole: Ludwig von Bertlanffy The concept of a system as an organization of parts that has characteristics that emerge from the fact of organization itself is the central concern of von Bertlanffy's approach to General Systems 'Theory. His early training in biology and the recognition that reductionism did not lead to a satisfactory explanation of the behavior of living systems led von Bertlanffy to consider the hypothesis that it was the noture of phenomena to react differently when considered as a whole rather than when considered as merely a collection of parts. While the emphasis on the whole (synthesis) rather than on the sum of the parts alone (analysis) is an old concept in Western thought, the ability to fumish a scientific basis for the assertion is new. In von Bertlanffy's work the role of cybernetic feedback 
is central to the concept of a system's

wholism.

The general systems aspect to von Bertlanffy's work emerged when he began to utilize these biological models to examine other areas of phenomena. His investigations proved fruitful in that many areas of inquiry, ranging from biology to physics and social analysis all proved amenable to consideration along wholistic lines when feedback was considered as a central mechanism.

His examination of a greater variety of phenomenia also led von Bertlanffy to consider the question of open or closed systems-that is the question of inputs to the feedback mechanisms that defined a systems boundaries. In all cases, however, von Bertlanffy asserts that feedback loops exist and are the primary mechaniam that define and maintain systems a recognizable structures.

In applying the paradigm then the principal concern-the problem-that defines the approach for von Bertlanffy is that of system maintenance. This maintenance is based upon the theoretical concept of homeostasis which 
in turn is supported by feedback. Change between systems is a result of positive feedback that continues until a new homeostatic state (negative feedback) is achieved. The theoretical basis of von Bertlanffy's model thus is a cybernetic loop.

Methodologically, feedback forms a basic model from which the boundaries of various gystems may be traced. This model is then applied to various types of phenomenia and the system is defined. Such identifications of common cybernetic processes in various disciplines is possible through the agency of mathematical analysis. While von Bertlanffy is interested in applying his cybernetic model to a wide variety of phenomena, most of his data base remains biological in nature.

Some General Characteristics of Systems

When we consider the particular aspects of the three authors that have been selected as representative of the concerns of General Systems Theory, certain common features of all of thelr orientations may be noted. There appear to be at least four common conceptions that are features of a notion of a system. We may consider these to be: Relational as 
against Classificatory concerns when considering phenomena; an assumption that a System possesses holistic characteristics; a recognition that a system needs to exhibit coherency; and finally a recognition that a system requires a ground or basis around which the relationships that constitute its locus ma be considered. I shall consider each of these four features in turn.

With respect to the relational as against the classificatory orientation of the logical operations of a system, this is fundamental in the definition of a system, at least in so far as General Systems Theory is concemed. Certainly the notion that a series of events or things related to one another is involved in a notion of a system; but if the emphasis is upon the event or thing other than the relationship, we end with a classificatory logic where the objective of the analysis is the clear specification of the nature of the event or thing; essentially an Aristolian position. If on the other hand the emphasis is placed upon the relationship per se, then we are only concerned with the object (event or thing) in so far as it is involved in the system. The objective of such an inquiry is with the outcomes of the set of relationships rather than with specification of the entities that are involved in the relationship.

This issue is of importance when we consider the problem of process rather than of classification. A dynamic mode 
requires that, consider the operations that obtain between entities through time rather than consider the character of the entity as such. This latter can only lead to a static descriptive analysis, it cannot produce a set of testable propositions that permit process statements. It is a tmism that most events; especially social events, are processual in nature so that any systemic account of these behaviors require a dynamic mode of analysis and so one that is relational in operative logic.

The concern with holism is also central to concerns with the behavior of systems. If systems concerns are dynamic and therefore relational in character, then the entire set of such relationships needs to be the basis of the sygtem. This focus on the entirety of the set of relationships is the heart of the holistic argument. The assertion springs fromthe observations that in many kinds of systems the resultant behavior of the whole is greater and of a different order than a summation of the parts (Ashby, 1960; von Forrester, 1969). Certainly this is true of biological phenomena, and even mechanical systems where the whole is seen as a sum of the parts, and that alone, can be seen as a special case of the holigtic mode in that the sum alone is a system (Buckley, 1968; Sahl, 1976).

Coherency, the notion that the relationships that constitute a systemic set share certain logical features, is a 
component of most concepts of a system. I'his leads to certain necessary qualifications. If a system possesses coherency it does not contain within its structure logical paradox, and so necessarily possesses those qualities that are part of the Theory of Logical Types-that is levels of interpretative relationship are part of the set of relations that make up the system (Bateson, 1972).

It is important to note that coherency does not mean homeostais per se. That is the error of structural functional theory. The control aspects of a system are cybernetics in nature, and are not necessary for the concept of systemic coherency (Weiner, 1948). Systems need not display control; they do need to display coherency if they are to avoid logical paradox (Bateson, 1972).

Finally, there is the problem of the grounding of the set of relationships that make up the systemic set. In the three authors considered in this section three different grounds for their consideration of systems may be found; viz. For Bateson, the basis of the relational set that constitutes the system is the exchange of information, and information serves as the focal point for the set of relationships that constitute a system. In Rapaport, the grounding is in mathematical formulations whereby the characteristics of the relational set are made clear, while in von Bertlanffy the ground is located in the boundaries that the set 
establishes for itself, much as occurs in a biological model. This variety of foci-groundings for the system-illustrate that a set of relationships, empty of specific content, provide the basis for conceptualization of a system. Indeed, it is the operational characteristics of these relationships that are the subject of General Systems Theory. When such operations are expressed coherently, with a sense of holism and with specified grounds, we are in possession of a minimal definition of a system.

\section{Application of the Paradigm to Information Theory}

Information theory had its beginnings in the 1940's when the problems of extending telecommunications capacity was considered in a new light. Up to that point when the pioneering work of Shannon and Weaver was made public, the increase of capacity of a telecommunications system was made physically. With the advent of a whole new industry following World War II, vast increases in the capacity of existing systems were needed. However, the use of physical meansstringing new wires, laying cable, etc.-made this impossible. I'he need was then to extend the utilization of existing means, and this required the mathematical analysis of the problem of message transmission.

Once the conception of a message as a code carrying bits of information was formulated, then the minimum number of bits of information that needed to be transmitted to carry a message code could 
TABLE III-2

COMPARATIVE CHART FOR THE PARADIGMATIC ANALYSIS OF AUTHORS ON INFORMATION THEORY

\begin{tabular}{|c|c|c|c|c|}
\hline Author & Problem & Theory & Method & Data \\
\hline aver & Communications & $\begin{array}{l}\text { Communications is the } \\
\text { ability to influence } \\
\text { behavior through mes- } \\
\text { sages. Information is } \\
\text { a symbol set which } \\
\text { makes up an informa- } \\
\text { tion. Noise corrupts } \\
\text { a message. Math sym- } \\
\text { bols are less sub- } \\
\text { ject to noise. }\end{array}$ & $\begin{array}{l}\text { Mathematical symbols permit } \\
\text { generalization as they are } \\
\text { without specific referents } \\
\text { in an empirical world, thus } \\
\text { they produce less noise. }\end{array}$ & $\begin{array}{l}\text { Tel ecommunica- } \\
\text { tions engineer- } \\
\text { ing. }\end{array}$ \\
\hline einer & $\begin{array}{l}\text { Cybernetic } \\
\text { Feedback }\end{array}$ & $\begin{array}{l}\text { Major framework of } \\
\text { modern science lies } \\
\text { in emphasis on prob- } \\
\text { ability and process } \\
\text { vs Newtonian con- } \\
\text { cerns with statics } \\
\text { and cause. New ap- } \\
\text { proach sees organi- } \\
\text { zation as coexten- } \\
\text { sive with communi- } \\
\text { cations network. }\end{array}$ & $\begin{array}{l}\text { Communications net is key } \\
\text { unit of analysis; network } \\
\text { is a set of feedback loops. } \\
\text { Communications net import- } \\
\text { ant because observers } \\
\text { filter all inputs. }\end{array}$ & $\begin{array}{l}\text { Optics } \\
\text { Autonama Theory } \\
\text { and Servo- } \\
\text { mechanisms. }\end{array}$ \\
\hline
\end{tabular}




\section{TA BLE IL I - 2}

(continued)

$\begin{array}{lllll}\text { Author } & \text { Problem } & \text { Theory } & \text { Method } & \text { Data } \\ \text { Ashby } & \text { Constraint and } & \text { Examination of con- } & \text { Identification of con- } & \text { Biological } \\ \text { Control } & \text { straints-set of pos- } & \text { straints permits manipu- } & \text { Phenomena } \\ & \text { sible functions. } & \text { lation. Rules of manipu- } & \text { lation then can be } \\ & \text { Addition of parameters } & \text { discovered. } \\ & \text { to the set-range of } & \\ & \text { variation for phenom- } & \\ & \text { ena. Rules about } & \\ & \text { parameters-basis of } & \\ & \text { testing had of change. }\end{array}$


be calculated. If in turn, human languages could be broken down into code that would be both aimple and accurate they could be sent economically and then re-translated at the other end of the communications chain.

The extension of the ideas of coding, message transmission in terma of form rather than content, and measurement of the flow of information contained within this theory brought immediate response from a number of disciplines; especially psychology, biology and the social sciences. These engineering concepts were extended to include other modifications in meaning. Many of these attempts to extend information theory were done without adequate theoretical understanding or comprehension of the limitations of the concepts. However, in some areas significant advances were made. When the theoretical matrix of the engineering approach was added to the phenomena of feedback, the ability of information analysis was made more explicit and the foundations were set for the many fruitful applications that now are made of information theory.

1. Information and Communication: Norbert Weiner

In Weiner's formulation, information flows along communications networks. These networks serve to carry messages that activate the system to perform cybernetically with respect to extermal or internal conditions. Thus, in Weiner's analysis there can be no cybernetic function without the transfer of communications. 
Such transfers may empirically utilize physical or symbolic transmission devices; but the manner of transmisgion has no effect on the form (code) or content of the message per se. Indeed, this nonspecificity of the means of tranamission is traced by Weiner to a major shift in scientific procedure from the Newtonian model of the 17 th Century to that used in modern times. The 17 th Century sought to deal directly with entities and so evolved into a static method of analysia. Modern science however, is statistical in nature, and as such, deals with distributive characterizations of frequencies of an entity's features. As such, modern science has as its focus dynamic analysis of processes. Modern science also realizes the intrugion of the observer into the empirical condition and seeks to control it through statistical means. The organizational pattern of the distributions of observations then becomes a communications network where in the feedback loops of observer to event and to other observers makes up the theoretical matrix of Weiner's conception of information theory. Methodologically 
this communications network is the unit of analysia. The network is defined by the structure of the loops it involves, and these are discovered by the cybernetic study of the behavioral relationships of different entities linked by the loops. A typical loop is described by a servo-mechanism; such as a thermostat. When the temperature drops below a present point the thermostat starts the heater, when it goes above a certain point it shuts the heater off. Ther servo-mechanism thus is a communications device that uses at least two different codes and concerns at least two different bits of information: temperature of the room is one bit of information and is collected in a mechanical manner. The startstop operation of the heater is a second type of information and this is accomplished electrically. The parallel behavior of the two nodes of the communications system-the heater and the thermostate shows that they constitute a communications network that is linked in a negative feedback loop. 'L'he data bases that weiner utilizes are far ranging in his works, they range from biological 
analysis of nervous systems as they maintain bodily processes in feedback loops to physics of optics where the nature of light may be more clearly understood in a systems manner than in terms of a fixed Newtonian approach. Weiner's major contribution to information theory has been the linking of feedback processes to the transmission of messages. Indeed, messages can only be understood if there is feedback; reception without resultant behavior is not meaningful. Communications thus demands a cybernetic aspect to information flow. Certainly in any social analygis communications applications of information theory are one of the major potential analytical instruments that are available to the social scientist or administrator. The study and analysis of behavior depends upon a communications network; both for the identification of the boundaries of the unit being studied and for the very process of study itself. The interaction of these two networks is a feature of all social intercourse so that Weiner's theoretical and methodological approach is a powerful instrument for application in these areas. 


\section{The Control and Constraint of Information:} Ross Ashby

Ashby's conception of information is more detailed and not as abstract as is Weiner's. In Ashby's formulation, information theory takes on more formal characteristics. Information is identified as occurring in sets (in the mathematical sense). Ashby is concerned with the analysis of these sets so as to discover the conditions whereby they may be manipulated. Once manipulation is possible then the rules of their relationships may be discovered and these will have the basis of scientific generalizations about the phenomena which the information concerns itself. Ashby's problem or focus thus is on the formulation of mules to control information. Theoretically the search for miles begins with the setting of constraints upon the possible sets. In this manner, possibilities are transformed into probabilities. For example, in a situation where a course of action is proposed. Initially there are a number of possible outcomes. At the beginning of a trip, there are many equiprobable directions to go. Once the 
set trip receives some constraint--such as "go to the store", the trip has narrowed the possibilities to a series of probabilities. The trip will be in the general direction of the store-say north. But as constraints are added, such as "in the fastest manner", only one possibility has a high probability. One rule then for the behavior of information is that as more constraints are added to a set, the probability of that set occurring increases. Once we have established a series of formal rules, and expressed them in a mathematical manner we shall have the foundations of a soientific analysis of behavior. Rules, once formulated are applied methodologically by observing their behavior over time. Thus, if different mules determine the behavior of social groups in different ways, as for example, in kinship systems, then only changes in these rules will permit the culture to change. In many social service agencies attempts to implement changes in client populations operate on a manifest behavioral level-such as housing, health care, etc., but never attack the problem of changing the rules 
that make the behavioral dysfunctions that are the object of attempted change. Ashby's conceptualizations are drawn from a number of sources, but his principal locus of application has been in biology and in attempting to duplicate biological processes mathematically. Thus, in his work Design for a Brain (1960) these two disciplines find common ground in his analysis of the conatraint setting mechanisms over information inputs that analytically is the analogue of thought.

\section{The Analysis of Information Processes:}

\section{Warren Weaver}

Weaver, and his colleague Shannon, were responsible for the initial explicit treatment of information in a mathematical framework. Their initial contribution has been mentioned previously. Weaver has continued to discuss the more general application of this approach so that the emphagis is less upon the technological application of these findings to telecommunications, but rather upon message transmission at any time with any media through any medium. Weaver's problem then for analysis is the character of a message, and what 
involved in its transmission.

Weaver understands communication to have taken place when one entity exerts influence upon another's behavior. This influence is exerted through a message. Such a message transfers information (which is indicated by the behavior change) usually in some form of symbol. In most human affairs the basic symbols are linguistic-speech or the written word. The ambiguities of these symbol systems leads to transmission difficulties; messages are often not understood or misunderstood. Such a diversion from the intended influence in a message is caused by "noise". Noise is thus anything that will distort the meaning of a message. Mathematical symbol system are both more general and less ambiguous than are either the written word or speech. The ability of a mathematical system to function as a more efficient, that is relatively noise free, system of communication is thus a major focus of Weaver's approach. Information that can be coded mathematically, and all information has some mathematical basis since all information is 
statistical in nature, will thus be more efficiently and unambiguously transmitted. Weaver's data base is essentially the material he developed in telecommunications where these concepts were applied.

4. Common Features of Information Theories

All of the three types of information theory we have considered share certain common features. These are 1 the concept of message; the process of feedback, the need for constraint, and the factor of redundancy. These four characteristics then form the basic frame of reference for the information code or "interpretative language" and will be utilized in the development of the analytical instrument that is the objective of this research.

The concept of message is central to all three conceptions of information. A message refers to the form of a communication rather than its content. Messages are sets of information that are transmitted through a medium, and upon reception cause some influence or change of behavior upon the receiving unit. Messages usually are in a code; and as Weaver points out the character of the code will 


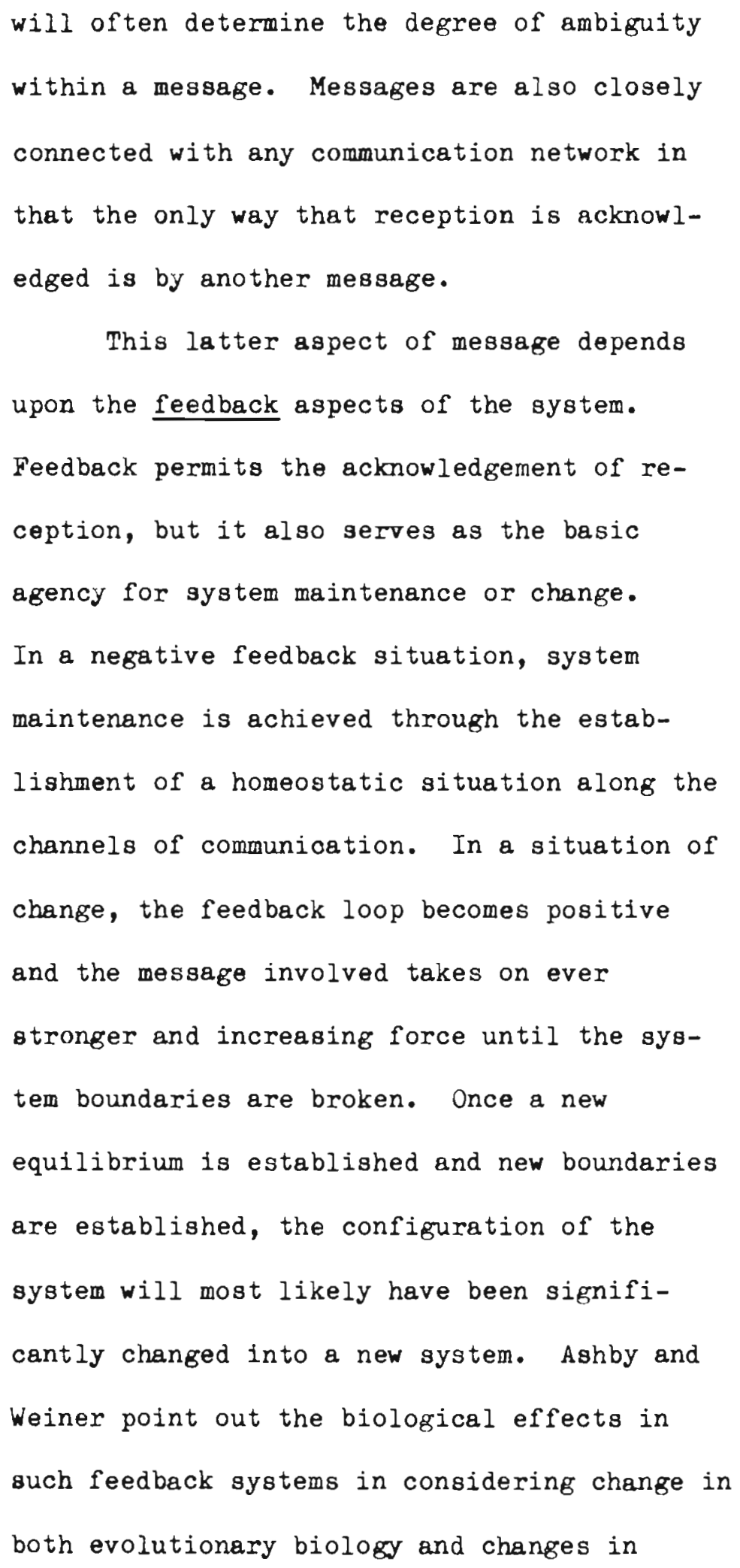


intellectual structures as well.

The third factor, constraint, is a feature that is important in the analysis of information flow along the network. It is, as Ashby notes, constraint that changes an event from a possibility to a probability. Constraints are the parameters that we add to any set of information that makes its directionality and probability more and more concrete. Constraint thus provides the basic parameters that give information the capability of being analysed.

Finally redundancy, is a factor that permits message decoding. Symbols attain meaning as systems only when they can be learned. The frequency of distribution of various symbols permits them to assume alphabetic character, and this demands not only constraint but redundancy. The constraints allow a symbol to have a frequency distribution, but the redundancy in the system over time gives these frequencies the character of rules. Written language may serve as an example. Constraints provide differences between 


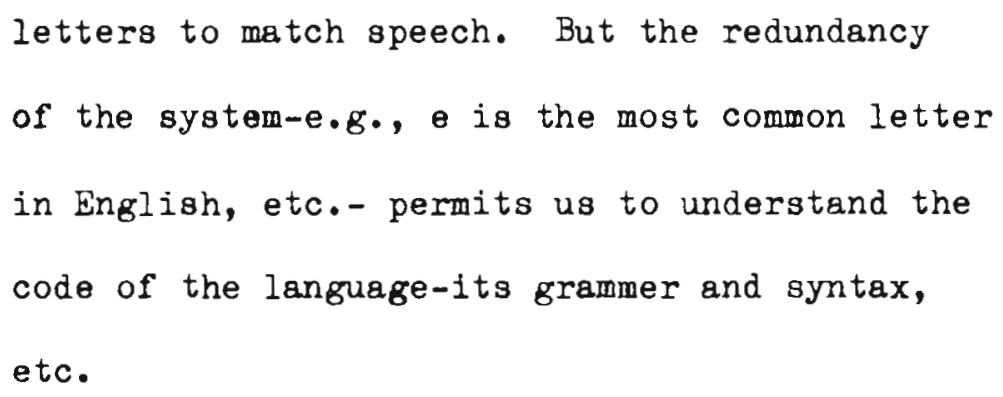

\section{Application of the Paradigm to Managerial Theory}

of the three basic "language types" concerned in this analysis; the role of managerial theory is most obvious. In almost all organized affairs, both governmental and private, there is a managerial role which seeks to rationally control the various processes that are being undertaken by the agency in question. The familarity of management does not however, mean that the theory that explains its behavior and seeks to make management more effective is fixed. The analysis of successful management is a product of the lat $19 \mathrm{th}$ century. The pioneering studies of Taylor (1911), Mayo (1946), etc., were supplemented by the work of sociologists who studied bureaucratic phenomena-Weber (1946), Merton (1968), Blau (1963), etc. This corpus of work has been more or less structured into what we may call Traditional Managerial Theory. Since the advent of high technology into managerial roles-the mass utilization of computers, modern systems analysis and ever greater complexity into private and public agencies, managerial theory has undergone geveral modifications. Two of the most significant of these are the emphasis of cost-benefit analysis and task-efficiency analysis into the matrix 
TABLE III-3

COMPARATIVE CHART FOR THE PARADIGMATIC COMPARISON OF AUTHORS ON MANAGERIAL THEORY

\begin{tabular}{ll}
\multicolumn{1}{c}{ Author } & Problem \\
$\begin{array}{l}\text { MBO- } \\
\text { Reif \& } \\
\text { Bassford }\end{array}$ & $\begin{array}{l}\text { Developing a } \\
\text { Cost-effective } \\
\text { Managerial } \\
\text { Tool }\end{array}$ \\
& \\
NASA & $\begin{array}{l}\text { Effective } \\
\text { Katilization of } \\
\text { Rosenzweig } \\
\text { high technology } \\
\text { and experts. }\end{array}$
\end{tabular}

Traditional Managerial Theory

\section{Theory}

Quantified results are of greater value than qualitative ones in management; objective measurement is scientific.

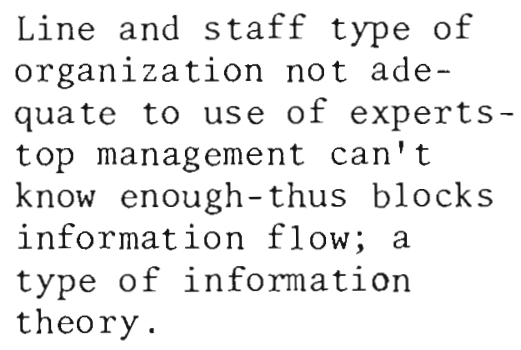
organization not adequate to use of expertstop management can't know enough-thus blocks information flow; a type of information theory.

Organizational structures mirror power; hierarchial basis for decisions. Goals tend to be qualitative to avoid rigid specification and to allow expansion of rules.
Method

Data

Define objectives that are measurable in order to measure most cost effective procedures.

Utilization of task forces built around particular tasks; avoid line and staff type of management.

NASA space projects.

Development of a rational line and staff around the hierarchial power

general.
Bel1 Telephone managerial practice. 
of traditional theory. This section will concern itself with the application of the paradigm to the analysis of these three foci in managerial theory as it applies to the process of decision making.

1. Traditional Managerial Theory

The locus of traditional managerial theory has been in the analysis of the effects and mechanisms that attend to hierarchial structuring in organization.

While hierarchial structures are found throughout the institutional bodies that exist throughout Western culture, the basis of hierarchial structuring in a decision making role is bureaucracy. This is especially true of social service agencies whether they are involved in planning, administration or the delivery of services. It is for this reason that this analysis of the traditional managerial approach will focus upon managerial operations in bureaucratic settings. In addition to hierarchial organization, bureaucracy possesses other features that are of concern to management analysis. Among these are the tendency for power to concentrate at the apex of the bureaucracy; the tendency of the structure to behave in such a manner 
that the structure will be preserved above any other consideration, and the tendency of a bureaucracy to seek to extend its sphere of jurisdiction. This latter tendency is related to the concerm for preservation; the greater the number of tasks encompassed by the bureaucracy, the less apt is the organization to dissolve upon completion of the task. Al1 of these tendencies and characteristics of bureaucracy illustrate the close relationship of structure to power. Bureaucratic organization and the hierarchial flow of power through it provide a political base from which policy may be implemented or changed. Traditional managerial theory seeks to understand this political element of management as well as recognizing the need for rationalization through the means of line and staff distinctions. Power, that is the ability to make and carry out decisions are conceptualized as a line function. There is usually a clear chain of command along the line functions, and power is concentrated at the top. Staff functions, historically added later, serve to provide expert advice at critical points along the 
chain of command. However, line and staff functions are always kept clearly apart and distinct. Power is always channeled along the line, and never from staff. E.g., in a managerial hierarchy a social worker could advise an agency head but could not make decisions about operations.

When this structural approsch is utilized in social service agencies, most bureaucratic administrative components of a social service system are middle line functionaries. Power is exercised through the agency, but is always reserved to the political body that controls fiscal affairs and hence decision making, apart from routine house keeping functions are reserved to units outside of the bureaucracy. I.e., funding for bureaucracy depends upon legislative decisions.

This split in the line function-where final decision making power is concentrated in bodies outside of the agency leads to a tendency in service bureaucracies to confuse staff and line functions. This violation of a basic tenent of managerial theory provides a clue to the inefficiencies that usually 
characterize service delivery bureaucracies. It also provides a basis for the innovations that characterize the changes made in managerial theory in the last twenty years. These innovations are discussed below.

In applying the paradigm to traditional theory we may identify the major problem that bureaucratic organization addresses itself to be (a) the preservation of the structure and (b) the control and supervision of the flow of information. We have discussed the relationship of bureaucracy to power above. The control of information flow is the only manner whereby administrative and managerial units can be arranged productive in a material sense, 8o that the only resource with which they concern themselves is information. Line organizations depend upon the control of knowledge. Information flow is usually restricted-in extreme cases on a "need to know" basis, and only the head of the organization has access to all parts of the operational picture. In practice of course, knowledge is less rigidly controlled, but there is a distinct tendency to restrict information flow only to what is 
needed for a particular level of organization to function (Weber, 1946).

Methodologically, bureaucracy operates with the instrumentality of line and staff. While line controls are usually clear and prescribed, staff functions are often a source of difficulty. The advisory nature of staff positions creates a sense of frustration on the part of participants, especially when advice is ignored or changed, usually for line reasons of which the staff remains ignorant. Staff functions are necessary for expertise within modern managerial structures; but staff advice will be sacrificed to preserve the line function-that is to preserve the bureaucracy. The data base for the theoretical model of the traditional managerial theory is enormous. A very large number of sociological studies have been made of bureaucratic structures. Among social service agencies there are classical studies of agencies such as Wiehe (1973); Kahn (1970). All of these studies however, tend to exhibit the characteristics that are outlined above. 
2. MBO - Management by Objective

The tendencies of bureaucracies to preserve and extend their domains can lead to a situation where the costs of operation begin to prove nonbeneficial. The overlapping of functions, arising from the tendency to expand spheres of jurisdiction in rival units of a bureaucratio structure not only duplicates activity, but delays the entire operation of the total bureaucracy. Economically such a situation leads to $108 \mathrm{~s}$ rather than profit; and even where some redundency is required in a structure, too much effort diverted into duplication will mean failure of the activity over time.

In an effort to minimize these tendencies to expand juriadiction a technique that modified traditional managerial approaches was developed; management by objective.

Management by objective (MBO) essentially seeks to clearly specify the mission of any bureaucracy or unit of a bureaucracy. This specification however, is made in measurable terms so that performance in successfully fulfilling the mission requirements can be 
objectively made. Once such measurements are possible, a more rational ordering of resources, priorities and the identificationof redundancies can be accomplished. The end goal of MBO is cost effectiveness in operations.

When the paradigm is applied to MBO several major differences between the approach and traditional theory become apparent. First, and most importantly the problem to which the technique addresses itself is cost effectiveness of operation whereas traditional theory is primarily concerned with maintenance and control. Moreover, this approach seeks to develop objective measures of performance so that effectiveness is capable of being expressed in economic terms.

The theoretical basis for this approach thus lies in the acceptance of the notion that objective, empirical measures that are capable of quantification are superior and lend themselves to manipulation and comprehension are better managerial instruments than are qualitative statements of goals that are characteristic of more traditional managerial theory。 Since the goal of management in $\mathrm{MBO}$ is 
efficiency (in economic terms) and the gorl of traditional organizations is system maintenance, the theoretical emphasis of MBO on quantitative measurement is different from that found in traditional managerial theory. (Reif and Bassford, 1973; Raider, 1975)

Methodologically the differences are more striking. MBO seeks to make costs lower, and to achieve this will tend to open up information flow rather than to restrict it as in the line and staff organizational structure that is characteristic of traditional managerial practice. While MBO does not do away with line and staff distinctions, nor with the chain of command concept, it does specify the tasks that each line and staff office has and provides measures of efficiency for their operation. With these constraints-public mission specification and the need to perform in a measurable manner-the tendency to restrict information flow beyond what is necessary should prove to be more difficult. Power relations are both changed and perhaps strengthened in MBO. The ability to control performance more directly as the technique 
Implies also means that more power is concentrated in the hierarchy. However, the flow of power (in bureaucracies this is always a matter of information flow) is more public and less liable to individual manipulation outside of the stated mission responsibilities for the untts of the bureaucracy. The data base for MBO applications, while not as rich as that of traditional managerial theory, still has several empirical case histories. The most notable example is that of the Bell Telephone Company where MBO is applied in management (Reif and Bassford, 1973).

3. Task Force Theory: NASA

The other major change to traditional managerial theory appeared in the last fifteen or so years. This modification of managerial concepts is more far reaching than that represented by $\mathrm{MBO}$, in that it involves structural changes in the line-staff approach to management that have served as the hallmark of traditional approaches.

Whereas MBO concerned itself with modifications to managerial approaches that sought 
cost effectiveness as a goal, task force approaches are a result of the information explosion that has attended the scientific and technological developments since the Second World War. Traditional managerial theory is hierarchial in structure, and the flow of information is from the top down. However, in areas where high levels of expertise and technology are involved, decisions require more data than can be handled by any one person. Staff-line relationships tend to be clouded by the division of responsibility from the action. In technical or expert situations the separation of authority from knowledge proves to be detrimental to both. It was in response to this latter problem that the taskforce approach to management was developed. The task-force approach to managerial operations however, depends upon the participants all being highly trained professionals so that respect for an area of expertise depends upon the information that the participant controls rather than on extraneous other factors such as status or age, etc. Thus, the innovation is limited by personnel 
considerations. In cases where such relationships can be established however, the task-force approach is highly successful.

The task-force theory of management depends upon clear specification of the various tasks involved in the activity being administered. Each task is then analysed as to what expertise is required and a task-force is organized around these requirements. The emphasis is on information exchange, and relations within the task-force, and between various tagk-forces are open in all directions. The hierarchial principle is thus changed into a situation where old line functions extend both horizontally and vertically. When the paradign is applied to this approach, the problem addressed is one of the effective utilization of highly technical or professional experts in a manner that facilitates information flow rather than controlling it as in traditional mode of management. Theoretically then, task-force managerial concepts are a variety of information theory. old traditional forms of hierarchial organization are correctly identified as being struc- 
tured to control and limit information flow, whereas such a procedure is wasteful and inefficient where highly skilled and technical information is involved. The method whereby task-force approaches increase the flow of information lies in the elimination of the hierarchial structure and the substitution of the task oriented grouping of a merged linestaff organization.

The clearest example of the successful application of this approach is in the operations of NASA. The National Space and Aeronautics Administration consists of large numbers of experts and professionals all developing new technologies and concepts. The traditional approach to the management of these activities ended in failure because the admin1atrators charged with managing the enterprise could not command the knowledge in all of the various complex fields to be able to make the necessary decisions. With the adoption of the task-force technique the programs moved ahead rapidly and much more efficiently. (Kast and Rosenzweig, 1972) 
There is a danger in the task-force form of administration however; efficiency and cost beneficial operations do not necessarily provide a political base for the maintenance and continuance of activities. The rapid shrinkage of NASA after the successful Apollo moon program is an illustration of this. Enormous success and clear ability in organization for achleving complex and difficult tasks were not rewarded or utilized in other areas. This need not have happened. The same organization could have been used to solve different taskse.g., problems of mass transportation, etc. This however, did not happen. The lack of a bureaucratic political base thus proved costly to the agency. Nevertheless, the task-force approach is a method for dealing with complex problems in administration where information flow requires enhancement rather than restriction.

Task-force approaches, while probably not suited to most social service managerial operations, may nevertheless have some scope for application. This is especially true in the planning and administrative areas rather 
than in areas of direct service. Since fiscal control will almost certainly remain in the province of the legislators, the level of fundIng determines the amount of direct service. 4. Common Features of Managerial Theories Comparioon of the three managerial theories leads us to the selection of their commonalities as the basis for a managerial

"language". These commonalities will serve as guides in the delineation of the managerial frame of reference which will form the basis of the predictive instrument developed in this thesis.

All managerial theories have an economic basis; all are concerned with costs, effectiveness, and efficiency. In addition, the theoretical concerns of all of these forms of managerial approachs focus on a goal or objective whereby the costs may be measured either quantitatively or qualitatively. The four concepts then: cost, efficiency, effectiveness and objective are the basic commonalities for managerial theory. Cost, clearly is not restricted to material expenses alone in management. There 
are costs in personnel affairs, delays or obstructions of information flow, retention of culture values that interfere with operations, etc. Costs may be evaluated in various ways; most often in management in social services the costs involved are in the form of various trade-offs that are involved when differing priorities-both fiscal and cultural-come into conflict. All forms of managerial theory reviewed here seek to make the system less costly overall, or to make specific the alternatives in areas where trade-offa are involved.

Efficiency, while related to cost is not synonymous with it. While the economic consideration of efficiency may indeed be closely tied to costs, economic indicators are not the only measures utilized in managerial activity. In social service administration other indicators such as physical or mental well being, individual rights, etc., are used as well ag cost. Efficiency thus is the most adequate performance of a task according to some index, whether that index is qualitative or quantitative is of no consequence. 
Effectiveness, is similar to efficiency in that it too is related to costs but has certain distinctions that are non-economic in nature. Effectiveness implies that certain priorities are involved in any managerial decision. In a complex situation, various subsystems may exhibit very efficient operations as subsystems. But the total system may suffer when subsystems operate independently of their mutual, but hidden total system goals. The effectiveness of the situation then may demand apparent inefficiency and high costs in some of its parts in order that the whole be able to function. Effectiveness then is related to the operation of the total system involved in the managerial enterprise.

Objective, or goal for managerial theory is a necessary part of the conceptual frame of reference. The indices that are used to conceptualize costs, efficiency and effectiveness all find their basis in the objective that is the end point for management. The specification of the objective may be specific as in MBO or task-force approaches, or relatively obscure as in traditional approaches; but all 
the theorieg require that a goal or objective be stated. Objectives may also be either static or dynamic. Traditional approaches tend to have dynamic objectives as a result of their tendencies toward "empire building", whereas MBO or task-force analysis often have more specific, and thus static goals. 


\section{CHAPTER IV}

\section{AN APPLICATION OF THE MODEL TO A REORGANIZATION EFFORT}

\section{IN SOCIAL SERVICE DELIVERY}

The previous chapter permitted the identification of the common elements that form the interpretative language or code for three basic systems approaches to decision making. In this chapter we shall utilize these common elements to construct an instrument whereby the model's predictions as to code usage and the success or failure of communications between subsystems may be verified. Unce the instrument is presented, it will be applied to a reorganization effort now proceeding in the Department of Human Resources of the State of Oregon. Unlike traditional structural-functionalism where the model would be applied post hoc to completed process (in this case a final form of a bill). The model is applied to data about the change process, i.e., bill drafts, L.C.'s, memos, letters, testimony, etc. The model's ability to deal with change processes as they occur rather than after the fact as in traditional theory will be illustrated by the ability of the model to predict the forms of communications utilized by the various groups involved in the subsystem and their ability to successful translate from one code to another. In addition, the model provides predictions of the probable outcome of the reorganization from a number of alternatives that are pending at this time. It does this by providing probability estimates as to the success or failure of the various bodies to 
"package" their proposal in an appropriate code. These predictions may be verified by the examination of the data-documentary examples that embody the code "packages" at various stages of the decision process. Time and budgetary constraints limit the application of the model to the analysis of the documentary material involved in the reorganization process. However, these elements have been supplemented by field observations and participation in some of the activities described below.

1. Construction of an Instrument

As has been noted, three basic codes have been identified as constituting the major interpretative schematas for a systems approach. Each of these codes has been reduced to a set of common elements that permits their being distinguished one from the other as to empha8is, manner of presentation of materials framed within the code, and most probable locus within the decision making structure as predicted by the model. These features will not be supplemented and extended so that the model's descriptive materials for each of the three codes may be applied to documentary evidence to illustrate the decision process. In these extensions two other features are necessary; the formulation of the common terms into a 
series of statements that are general descriptions of the typical contents and forms of communication for each code, and some empirical examples of materials that express the language form of the code.

Table III-1 provides a convenient form whereby the characteristics of each of the three codes may be compared. In formulating the generalized picture of a code's typical contents, a modification of the processes of content analysis was utilized (Riley and Stoll, 1968). Three foci for such typical contents were selected; the basic orientation used, the type of terminology, and the typical audience addressed. These three features permit sufficient identification of the code when it appears in various empirical forms or documents.

The orientation feature refers to the type of issue that the code addresses itself or to the basic framework into which an issue is forced as a result of the use of the code in question. Thus, in a general system theory code, the orientation is very general; it seeks no detailed specific set of directions 
in decision making but is utilized best in making clear all of the implications of a proposed course of action throughout the whole system. An information code is, on the other hand much more specific and technical in nature. Its orientation is to be optimization of the flow of information within a specific interface. As such, the orientation of communications in this code are typically highly detalled and technical in nature. Managerial codes on the other hand, are even more specific in their orientation. They are typically not only detailed, but restricted to a political or economic outcome orientation. The three codes thus offer a spectrum ranging from a very general orientation of general systems theory to a very specific and restricted code in managerial theory.

This spectrum of degrees of generality is mirrored in the typical terminology used in the codes as well. General systems theory codes often find expression in relatively ordinary language, at least as far as social analysis is concerned (von Bertlanffy, 1972 ; Klir, 1969; Fried and Molnar, 1975). The use 
FEATURES OF THE THREE BASIC SYSTEMS CODES: THEIR CONTENTS AND DOCUMENTARY EXAMPLES

\begin{tabular}{|c|c|c|c|c|}
\hline $\begin{array}{l}\text { Interpretative } \\
\text { Code }\end{array}$ & $\begin{array}{l}\text { Basic Common } \\
\text { Terms }\end{array}$ & $\begin{array}{l}\text { Locus of Interface } \\
\text { of Mode } 1\end{array}$ & $\begin{array}{l}\text { Typical Contents } \\
\text { and Audiences }\end{array}$ & $\begin{array}{l}\text { Empirical and Documentary } \\
\text { Example }\end{array}$ \\
\hline $\begin{array}{l}\text { General } \\
\text { Systems } \\
\text { Theory }\end{array}$ & $\begin{array}{l}\text { Relational } \\
\text { logic } \\
\text { Holism } \\
\text { Coherency } \\
\text { Ground }\end{array}$ & $\begin{array}{l}\text { Public/voter with } \\
\text { Politician/repre- } \\
\text { sentative }\end{array}$ & $\begin{array}{l}\text { General issue } \\
\text { orientation } \\
\text { Common language } \\
\text { Vocabulary } \\
\text { General public } \\
\text { as audience }\end{array}$ & $\begin{array}{l}\text { Press releases; } \\
\text { Political speech } \\
\text { Public testimony in } \\
\text { Legislature }\end{array}$ \\
\hline $\begin{array}{l}\text { Information } \\
\text { Theory }\end{array}$ & $\begin{array}{l}\text { Message } \\
\text { Feedback } \\
\text { Constraint } \\
\text { Redundancy }\end{array}$ & $\begin{array}{l}\text { Public/client with } \\
\text { Bureaucracy/Service } \\
\text { Delivery } \\
\text { Political/Fiscal } \\
\text { with Political/ } \\
\text { Representational }\end{array}$ & $\begin{array}{l}\text { Specific, detailed } \\
\text { orientation } \\
\text { Technical } \\
\text { Vocabulary } \\
\text { Technical audience }\end{array}$ & $\begin{array}{l}\text { Fiscal analysis of a } \\
\text { budget } \\
\text { Legislative questions } \\
\text { to bureaucracy on } \\
\text { operations }\end{array}$ \\
\hline $\begin{array}{l}\text { Managerial } \\
\text { Theory }\end{array}$ & $\begin{array}{l}\text { Cost } \\
\text { Efficiency } \\
\text { Effectiveness } \\
\text { Objective }\end{array}$ & $\begin{array}{l}\text { Bureaucracy/Delivery } \\
\text { with Bureaucracy/ } \\
\text { Managerial } \\
\text { Bureaucratic/ } \\
\text { Managerial with } \\
\text { Political/Fiscal }\end{array}$ & $\begin{array}{l}\text { Economic or polit- } \\
\text { ical power } \\
\text { orientation } \\
\text { Jargon } \\
\text { Subordinates as } \\
\text { audience }\end{array}$ & $\begin{array}{l}\text { Manuals of rules and } \\
\text { administrative } \\
\text { regulations }\end{array}$ \\
\hline
\end{tabular}


of technical terms and jargon is minimal, being conditioned only by their use in those areas that are being integrated by the theory at the time. Thus, in Beteson's work, the number of technical terms used in the analysis of information exchange or psychiatric problems is far less than occurs in a typical article in joumals that are characteristic for those fields alone.

Information languages tend to utilize a technical code. The close association of information theory and engineering leads to the proliferation of technical terms that have detailed, and in many cases well specified meanings that are capable of mathematical expression. (Weaver, 1949) This technical vocabulary, while unfamiliar to social scientists, has its analogue in the technical languages that are used in decision making when either fiscal or management information processes are applied to agency behavior. PERT, or other variations of the critical path method are not less technical in their applications than some of the more classical engineering applications of information theory (Miller, 1963; Hetrick, 1963). 
Managerial languages are of ten the most

jargon ridden vocabularies having in many

cases evolved through a bureaucratic process

where all of the forces that make for the control and limitation of knowledge are expressed in very detailed form. Jargon may be distinguished from a technical language in that a technical term seeks to clarify a concept and restrict its ambiguity while jargon only seeks to accomplish this while in fact increasing ambiguity. The rules and regulations that are the heart of any social service delivery system provide excellent examples of the effect of jargon in attempting to apparently reduce ambiguity while still maintaining control of information. Indeed, the need for technical interpretation by the Attorney General is often the only way out of an Impasse that is created by excessive use of jargon. (e.g., thus in an opinion request $\mathrm{OP}-3661$ by Department of Human Resources to Attorney General:

"Your second question is whether there is any difference in the meaning of the term 'actual consumers of services under the aging programs,' as used in the state statute, and 'actual consumers of services under this 
program,' as used in the Federal regulations. The two terms have exactly the same meaning in their respective contexts."

Finally, the character of the audience needs to be considered. The model identifies the most probable use of a general systems theory code on the part of politicians interfacing with the public in their representational and voter aspects. The audience thus is usually the general public and the empirical example of such interface documents are press releases, political addresses by politicians where they discuss a general issue-such as the needs for the elderly; and public testimony by citizens before legislative committees. Information theory codes, being much more technical, usually finds its audience in social service area in the legislative fiscal aspect. When not addressing the public, the legislative decision maker is concerned with the fiscal constraints that are the means of legislative control over the bureaucracy. The audience for such inquiries is thus technicaland finds expressions in budget analysis of various programs and the types of questions that are asked of budget makers in committee 
hearings. With respect to the public-client and bureaucratic delivery system interface, the information theory finds expression in such technical problems as establishing eligibility for a program. The real audience here is not the client but the bureaucrat; the client needs to satisfy the requirements established for him, rather than having agency personnel service his unspecified needs. Managerial languages are often restricted to "in-house" operations of the agencies involved in the administration and delivery of services. While managerial language codes are not always used in a strict line-staff manner; in most social service delivery systems they are organized in the traditional manner. Such traditional managerial languages are addressed to subordinates as their audience, and seek with the aid of jargon to both maintain the subordinate-superordinate relationship and to protect the superior with ambiguity. Examples are clearly such documents as rules and regulations that govern administrative procedures for an agency. 
2. Background of the Problem of Analysis

The State of Oregon is undergoing a decision making process with respect to the reorganization of the Department of Human Resources. More specifically there is the question of the place of various programs for the elderly within these organizational efforts. This area was selected for the application of the model since all of the elements of the model-public, bureaucracy and politicians are involved with these problems in decision making, and the availability of materials and field experiences made the data more easily available for analysis. Finally, while the actual decision in the matter is not yet forthcoming; the model should predict the most probable outcome of the decision process. The case thus provides a potential for verification.

The issues involved in the reorganization of the Department are complex and have several latent and manifest characteristics that are in many ways opposed to each other. In presenting the background to the various policy options that rre the heart of the 
decision process, the various manifest and latent aspects of the issues that developed over time will be presented. Various documents illustrating the developing phases of the decision process will then be noted, and their operational code analysed. The model, having predicted that proposale that are "packaged" in a code that is mutually comprehendable will more likely find support, will then be applied to the actual events and their expressions in documents. From this application, predictions as to the probability of various alternatives will be made along with an analysis of the potential problems that proposed changes might cause in the communications network of the Department of Human Resources and programs affecting the elderly.

The various issues that evolved over time and the manifest and latent aspects that formed the basis for the problem's evolution along the lines described are summarized in Table III-2.

The 1971 legislature established a Department of Human Resources that set up an administrative structure for many programs 
TABLE IV -2

\section{MANIFEST AND LATENT ASPECTS OF THE REORGANIZATION OF DHR DECISION PROCESSES}

Issue

Need for more efficient organization; DHR has responsibility but no authority, too dependent on PWD.

Programs for E1derly get Federal support; many senior citizens need assistance but don't meet PWD eligibility criteria.

Reorganization is proposed.

Prevention of PWD division from controlling DHR.
Manifest Aspect

Inefficiency of DHR management; most programs are funded (and thus controlled) by PWD which is outside of DHR.

Programs established outside of PWD to assist elderly:

-SPOA-administers funds to local AAA .

-Project Independence for those not on welfare.

-Governor's Committee for advocacy.

Simplification of administration and cost-beneficial cuts in current duplication.

Division status equal; DHR makes up budgets for all divisions.
Latent Aspect

PWD dominant in human services and is increasingly bureaucratic; power is extending into policy areas, politicians face losing control.

SPOA acts to establish a counter bureaucracy to PWD.

E1derly programs and Project Independence suggest PWD is too limited to be independent of DHR .

Governor's Committee is in advocacy role and is used to support reorganization.

PWD will be brought under DHR, as well as SPOA, Elderly Programs and Project Independence. Aging programs to be a division along with PWD.

Administration of DHR unclassified; less bureaucratic.

The established political base amongst elderly gives politicians countervailing power in running DHR . 
involving the delivery of social services. However, a basic failure, at that time was the exclusion of the Department of Public Welfare from control by the Department of Human Resources. Since much of the funding of programs in DHK was controlled through the Public Welfare Department, there was a separation of responsibility from authority in the operations of DHR. In addition, the procedures and legislative restrictions on PWD operations led to a certain amount of public demand for reform. Many elderly people thus needed services, but did not meet the requirements of the PWD. This structure was partially the result of an awareness of the legislature of a cultural problem, e.g., many elderly will not use Public Welfare. So that elderly people were made separate from PWD. (Minutes of Sub Comittees \#4, ways and Means, 5-20-75) These facts, in addition to a growing concerm nationally and throughout the State with the elderly led the Federal government to make avallable various funds for aiding the elderly. These manifest features of the issue of the need to reorganize DHR mask other political 
problems that while latent, are perhaps more important in the impact that they exert upon the decision process.

The tendency of bureaucracy to expand has already been noted. The danger in this is that the bureaucracy will encompass policy making as well as administration within its preview. Such a development is both poor administration, and more seriously leads to a loss of individual liberty (Kaufman, 1968; Lang, 1968; Simon, 1968). The power of PWD over the control of human services is immense, and PWD was politically successful in maintaining its autonomy from policy control when it avoided being placed under DHR in 1971. The funding avallable from Federal sources for programs for elderly citizens thus provided the Governor with a means to create a series of programs outside of PWD-in this case the Governor's Committee on Aging; Project Independence and State Programs on Aging (SPOA). This apparent diffuseness of efforts saw successful in establishing a need to reorganize DHR, and include PWD within its preview. In addition, the various functions- 
Project Independence to service those whose need assistance without meeting PWD qualifications; the Governor's Committee advocacy role, etc., formed a political base to accomplish this reorganization.

3. Examples of Documents Reflecting the Three Codes

Table I-l locates the six interfaces, within and between subsystems in the model. Since we have previously eschewed the analysis of the public interfaces, at least on the public/voter-public/client locus, we shall present only typical documents to ullustrate the remaining five interfaces.

a. The Public/Voter-Politician/Representative

Interface (B in Figure 1)

In context of the problems of reorganization of $\mathrm{DHR}$, and the latent poliical utilization of the various programs for the elderly to accomplish this end, appropriate documentation for this interface will be found in the materials provided by the Governor's Committee on Aging. The minutes of these meetings, as well as news releases and press coverage of the adrocecy aspect of the Committee-the 
Coalition of Senior Advocates all provide examples of the type of materials that represent this interface. As the model predicts, those documents that express themselves in a General Systems Theoretical code emphasizing general issues rather than detailed specific ones in common language are successful in this regard. (Minutes meetings of GCOA; press releases) An example of the Minutes of the Govemor's Committee on Aging for January 21, 1977 includes the following material. This discussion of energy costs by the Utility Commissioner of Oregon is an example of the use of a General Systems Theory code, that is it is a broad overview and not a specific technical or jargonistic expression.

Charles Davis, Utility Commissioner of Oregon, spoke on utility problems. He discussed the role of the Govermor's Committee. It should provide protection and not unnecessary regulations. He talked about the role of regulation. He explained how rates were discussed and regulated. $\mathrm{Mr}$. Davis mentioned that 70 percent of our natural gas supply comes from Canada. He mentioned the rural electrification problem. 
The role of public and private utilities was explained. He discussed Bonneville Power Administration. Also, he stated that at present time, he could not set a separate rate for parts of the public. He explained the State Bnergy Authority proposal of Governor Straub which would try to buy electrical power from Bonneville Power Administration and then sell it to users of electricity. Bonneville Power Authority is discussing now with the private utilities some cooperative arrangement to purchase all the electricity and then ration it to the users. Dick Wilson asked about the role of utility advocate for older people. Charles Devis reported that they are working on changing the rules, but he felt that it was bad for sections of the population to get discounts. The State should decide. Walter McGettigan thanked Charles Devis for his presentation and time.

The newspaper release reproduced herein

present another example of General Systems Theory coding in that they are meant to appeal

to the general public.

b. The Political/Representative-Political/

Fiscal Interface ( $D$ in Figure 1 )

This interface is best represented

by the materials found in legislative

questioning of the services of Legisla-

tive Fiscal. The latter institution is 


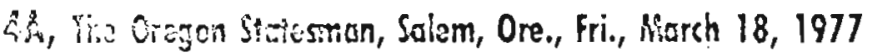

\section{Bohlenecks seen in programs for the elderly}

(Fron Page 1A.) Straub listed among his legisuctive rriorities for the eiderly: properly ano reibit tas rater, utility ratis restei, money for pro. grons: to inssilate the hone: of low-income eldoriy and icr in-home help is heep senior citizens out di rulon? homos.

Whi lor goverrer did noi dicevess in his beishalibe jarer is an repparent Lotalcuces in the administration of elderly proînisis.

The: more scrsitive subter cane up Ihulsolay

elderly - both lodged in the Deparment of Human Resources - have had what could best be described as correct but cool relations.

Which should be merged afternoon during a meeting of the House Committee on Aging.

The problem is this:

There is a State ProGrim on Aging which ad. ministers money the state receives from the federal Older Americans Act. That money passes through the state program ard is lunneled down to local aging programs, such as the Mid-Willamelte Valley Area Agency on Aging.

The local programs spend the funds in such areas as homemaker ser-

into the other is a touchy question that both the aging Commitee and the Human Resoures: officialdom are on llae verge of addressing.

Bob Oliver, assisians hia- vices, senior hot meals, senior bus services and health screening programs.

There is also the office of the special assistant on elderly affairs who administers state money allocated by the 1975 legislature under Oregon Project Independence.

That money also goes down the same circuil to local homemaker pro. grams, senior hot meals, bus services and health screening.

In addition to both aging programs, the public wel- fare division also provides money to elderly welfare clients for homemakers and some health programs.

Confusing? The legislators thought so.

Everyone publicly agrees that less duplication in administration would mean less public confusion and presumably less cost.

But where there is mon. ey there is politics.

The State Program on Aging and the office of the special assistant for the man resources din sidd a pan for dirbint overtap uill en pesen

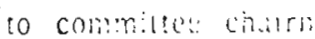

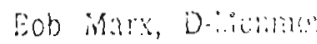
nexi acos. 
the financial research arm of the legislature as a counterbalance to the budget requests of various administrative agencies.

Such a report and the minutes directing that it be made are to be found in Hearings of the House Committee on Aging for January 20, 1977, where the Legislative Review Office presented materials that analysed the effects of $\mathrm{HB} 2040$ dealing with Property Tax Relief. Although this is not directly connected with the proposed reorganization of DHR, the document is typical of the expected information coding of Legislative review analysis, while the legislator's own questions reflected a more general systems theory orientation. The Review office material is detailed fiscal analysis of the effect of changes on property tax relief, while the House members sought more or less to assess the effects upon programs for the elderly as a whole, and certainly on the revenue picture of the State as a whole. The model predicts that 


\section{HARRP RETURNS PARTIAL OR FULL RELIEF, BY HOUSEHOLD INCOME, MOBILE HOME}

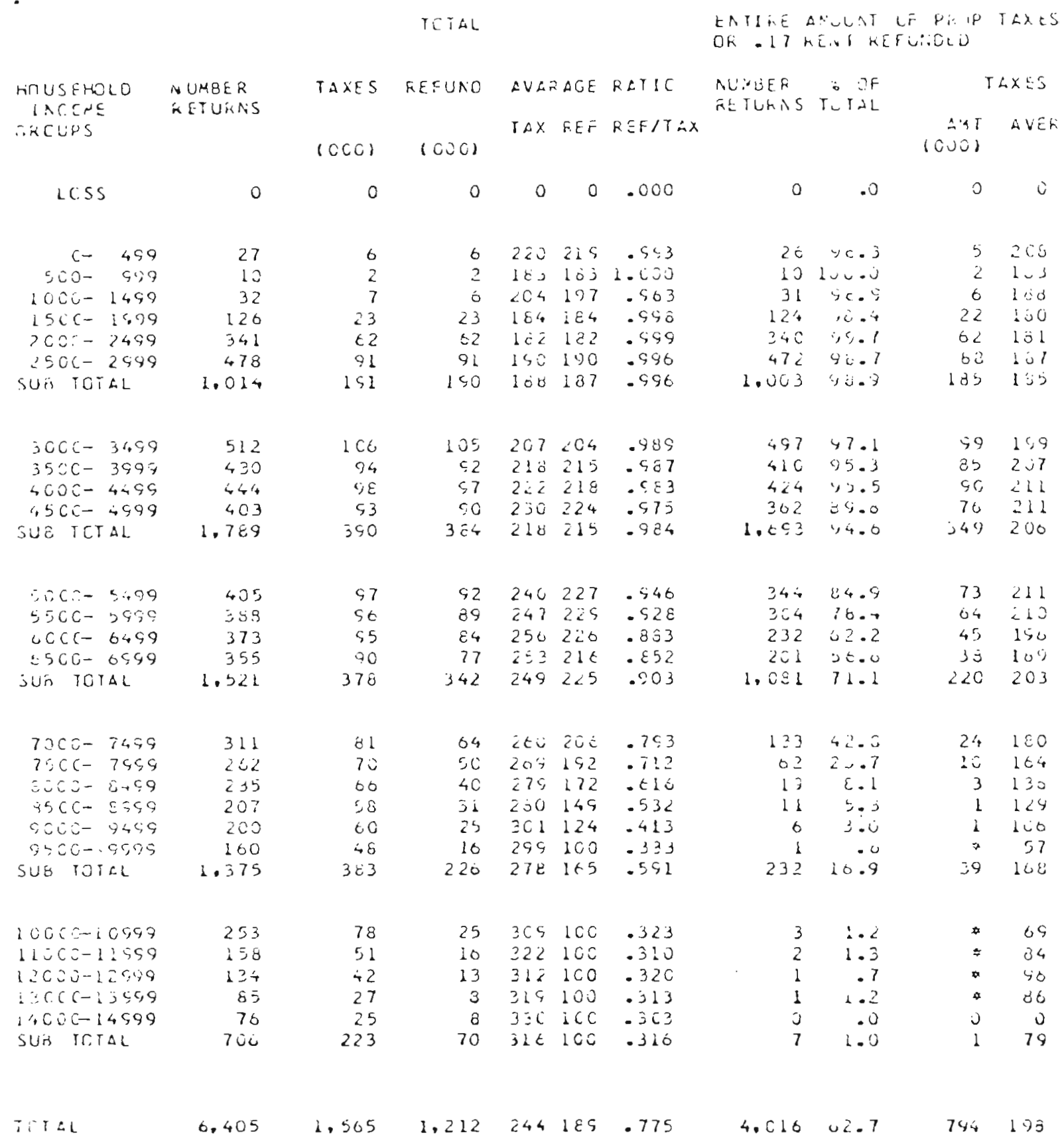


1975 HARRP RETURNS PARTIAL OR FULL RELIEF, BY HOUSEHOLD INCOME, MOBILE HOME

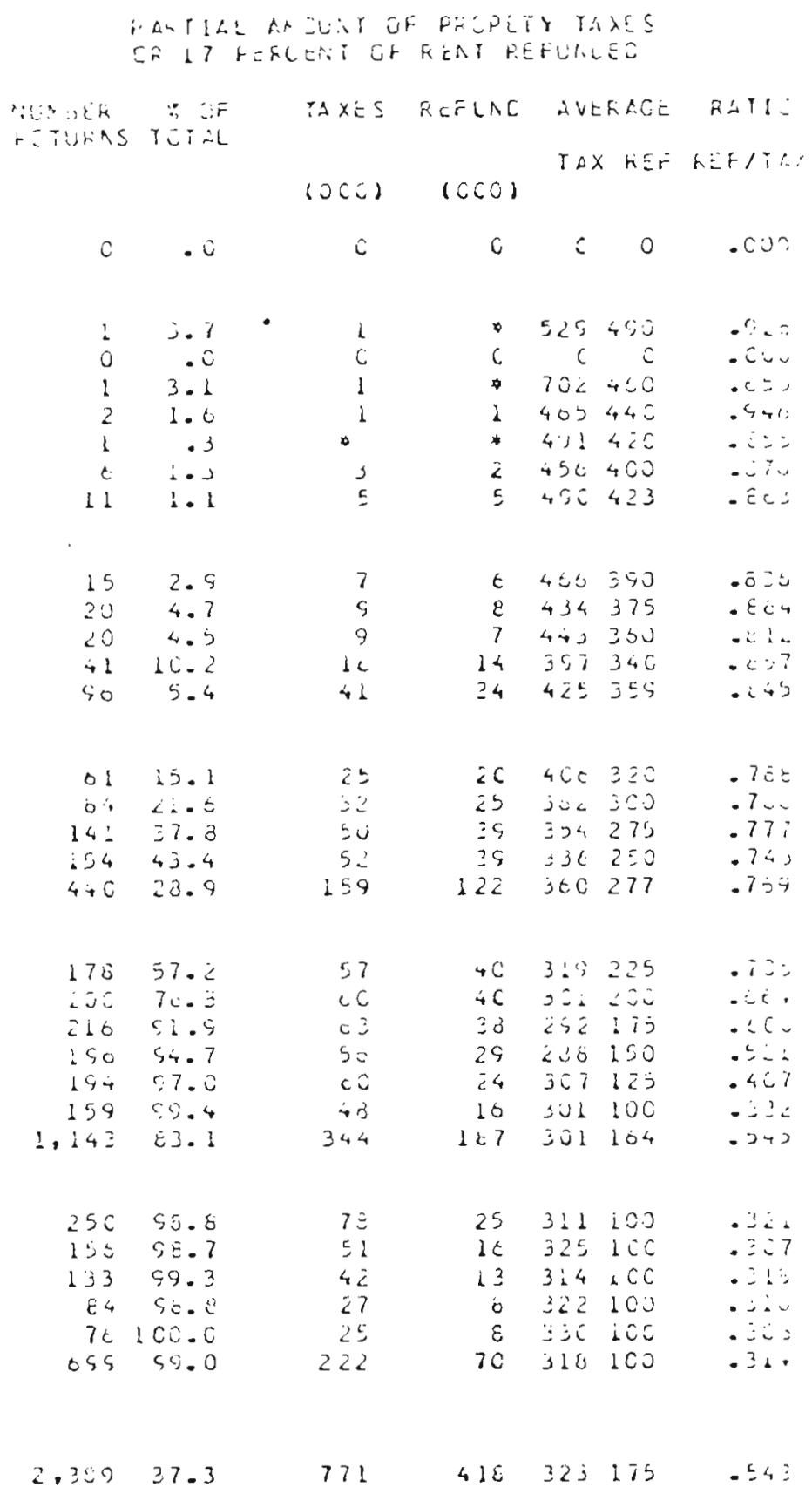


when the reorganization package reaches the point of analysis by Legislative Review and Legislative Fiscal Offices, this same use of technical codes will repeat. c. Bureaucratic/Managerial-Legislative/ Fiscal Interface ( $A$ in Figure 1 )

The materials that are characteristic of this interface may be found in such testimony as is presented by senior bureaucratic officials to Legislative committees. Thus, in the testimony of the Deputy Director of $\mathrm{DHR}$, a prepared statement dealt with the various duties and assignments of Special Assistant for Programs for the Elderly.

The 1975 Legislature also created the position of Special Assistant for Programs for the Elderly, within the office of the Director of the Department of Human Resources. The Special Assiatant by law serveg as Executive Officer of the Governor's Committee on Aging. By law also, she assumes responaibility for statewide advocacy for senior citizens and articulates recommendations of the Governor's Committee on Aging. Clearly, the statute gives Mrs. Shepherd two hats to wear--one a member of the director's staff, and the other ataff for an advisory committee. In giving her statement, and in responding to questions, she will carefully identify the hat under which she is speaking.

Mrs. Shepherd's ongoing assignment is administration of Project Independence-- 
a program established by the 1975 Legislature intended to defer, as long as possible, institutionalization of the elderly

Another example of managerial code usage is to be found in the testimony of the Director of State Programs on Aging. 


\section{CURRENT AND PROPOSED PROGRAMS FOR THE ELDERLY}

\section{STATE PROGRAM ON AGING}

\section{Introductory}

The State Program on Aging was established in March, 1967 following passage by the Congress of the Older Americans Act of 1965, approval of Oregon's State Plan by the Administration on Aging, and approval and appropriation of required general fund match by the Oregon Legislative $\mathbf{s s e m b l y . ~ N o w , ~ a t ~ t h e ~ o n s e t ~ o f ~ t h e ~}$ program, the state is required to match only those federal funds coming into the state for state agency operation. Required matching funds for federal fund allocations for community services for the elderly are met locally. The federal funds for services in the states have always been allocated on a population formula: initially, on the basis of each state's population 65 and over, currently on the basis of the state's population 60 and over。

On July 1, 1976 there were 368,904 persons over 60 years according to estimates by the State Program on Aging. This is $15.8 \%$ of the state's estimated population of 2,332,000. Of this group 264,982 are over 65 or $11.4 \%$ of the state's population.

The state's population is projected to increase $16.9 \%$ over the next ten years. The number of persons over 65 will increase by $21.0 \%$ and the number of persons over 60 will increase $17.6 \%$ 。 Persons over 80 will increase $17.6 \%$ over the same period but women over 80 will increase by $21.6 \%$ resulting in a higher proportion of widows over 80 .

It is estimated that as of July $1,1976,64,920$ persons or $17.6 \%$ of those over 60 made less than $\$ 3,800$ per year and therefore were below the poverty level. SSI recipients over 60 total 12,315 or $3.3 \%$.

The elderly comprise the largest segment of the chronically disabled, suffering from such allments as loss of sight, hearing impairments, and impaired mobility.

This state agency carries the responsibility of bringing together resources to address the needs of older Oregonians, irrespective of funding source public or private. While federal funds for services have increased markedly (from approximately $\$ 200,000$ in special payments for the 67-69 biennium to $\$ 8$ million plus in the 77-79 biennium) Congress has never intended that Older Americans Act funds encompass the service needs of older Americans but that 
these funds serve a catalytic purpose in the generation of other resources.

Working within the designated state agency, the Department of Human Regources, the Program on Aging as the single organizational unit has the delegated authority for implementation of the federal Act which include responsibilities for statewide planning and coordination of aging programs, along with specific responsibilities for administration and monitoring of programs funded through the Older Americans Act and Oregon Project Independence. The agency is not a direct service provider but through funding makes possible the provision of services locally.

In implementation of the above responsibilities the state agency has developed through federal mandate (the Amendments to the Older Americans Act of 1973 and 1975) a network of Marea agencies on aging" and other funded programs located in each of the 14 administrative districts. These organizations are to plan, coordinate and develop resources for a system of comprehensive services for the elderly within the local area. By granting funds from Title III (Community Programs), Title IV-A (Training), and Title VII (Nutrition) of the Older Americans Act and by contracting for services under Oregon Project Independence (altemate care services to institutionalization) with the Area Agencies and programs outside area agencies, the Program on Aging attempts to assure, through technical assistance and ongoing monitoring and assessment, quality service to the over-60 population of Oregon in greatest need - the low-income, minority elderly including those at "highest risk" of premature or inappropriate institutionalization.

Examples of services funded are: transportation, escort, health screening and education, homemaker and in-home services such as home repair, winterization, chore and housekeeper services, hot meals at congregate meal sites, home-delivered meals to the homebound, outreach, information and referral with follow-up, etc.

II. Current and Proposed Hrograms

\section{A. Funding Levels}

The major source of federal funding comes from two Titles of the Older American Act, Title III (State and Commuity Service Programs) and Title VII (Nutrition Program for the Elderly). Current annual funding levels as appropriated through the fiscal year 1977 Labor/HEW Appropriation Bill are as follows:

$$
\begin{array}{llr}
\text { Title III } & - & \$ 1,328,702 \\
\text { Title VII } & - & 2,216,399
\end{array}
$$


These funds are available through September 30, 1977.

B. Allocation of Funds

The fuads are allocated to the area agencies and other funded programs in each of the state's 14 administrative districts on the basis of a formula which includes several factors: $60+$ population, $60+$ below poverty level, $60+$ minority population, and a land mass factor to accommodate distances to and from services in the many rural areas of the state.

In advance of the preparation of an annual plan by area agencies for utilization of III and VII funds, then, the allotment to each of the districts is already known. The annual plans are prepared by staff with the continuous involvement of Advisory Councils of which over half the members are elderly consumers of the funded services. Additionally, public hearings are held in each local area statewide prior to submission of the plan to the state agency for approval.

C. Priority Services

The 1975 Amendments to the Older American Act specified four priority services for dunding under the Title III State and community programs. The services are: transportation, legal counseling, residential repair and in-home services. Oregon already meets the criterial specified in the Act in that we are already using one-third of our Title III allotment to provide some or all of the four priority areas. Currently, only minimal dollar amounts are going into legal counseling in our state. We find primary attention focussed on in-home services.

\section{Programs}

Originally, Area Agencies on Aging numbered 7 in 1973 -- we anticipate 15 in the new biennium. Also, nutrition projects have increased from 5 in 1973 to 12 presently with 2 more to be added in the new biennium. We do not anticipate any substantive or major changes in the funded services currently in place except for expansion or strengthening of services as federal funding levels increase. For example, the federal allotment of Title VII nutrition funds to Oregon has more than doubled since 1973.

In the first quarter of the fiscal year ending September 30, $1976,24,121$ different individuals were served by the Nutrition Yrograms in the state either at congregate mealsites or through home-delivered hot meals. In this quarter ending September 30, 1976302,463 meals were served. In this same quarter, 15,556 elderly were provided transportation, 
20,238 information and referral services, 6,077 were contacted through outreach activity, 561 were provided escort service to medical services, meal sites, marketing, etc., 64 received home services of one kind or another. Our year end report showed 1,400 individuals receiving homemaker services, 2,185 received a variety of other services.

All this information applies only to services federally funded.

January 18, 1977 
These presentations are in a managerial code, whereas the Minutes of the Hearings before which the Testimony was heard indicates that the legislative members questions tended to emphasize a fiscal-information coded approach. Thus, "Representative Marx asked for information on the numbers of individuals served in each are by category," emphasis added. The Deputy Director said that such information would be supplied. The response to the questions of the legislature was in clear contrast to the bureauoratic managerially coded testimony of the senior officials. The successful information coded packaging of the data requested is illustrated in the "Summary Statement of Elderly Programs in DHR" presented to the Committee on March 17, 1977. One page of the report is included as an example of this successful packaging. 
As requested by Housing Committee on Aging

Representative Robert Marx, Chairman

\section{ONE RECENT MONTH*}

Program Administration Description of Services Provided Caseloads

Total

PUBLIC WELFARE DIVISION

Aid to $B 1$ ind $(A B)$

No age requirements

581

Funding

Expenditures

Eligibility

\section{A11 Genera 1 Fund \\ $\$$ \\ $21,605.28$}

$\begin{array}{lr}\text { Medical: Old Age } & \\ \text { Physicians } & 3,690 \\ \text { Hospitals } & \text { NA } \\ \text { Nursing Homes: Skilled } & 457 \\ \text { Nursing Homes: Semi-Skilled } & 6,193 \\ \text { Drugs } & 7,822 \\ \text { Dental } & 181 \\ \text { Transportation } & 598 \\ \text { Visual } & 185 \\ \text { Miscellaneous Medical } & 340 \\ \text { Medicheck } & 22\end{array}$

* Both skilled and semi-skilled payments

\section{AFC/GFC}

Special Funding (GFC)

Home for Aged Non-ICF

Hous ekeepers

Homemakers

Home Delivered Meals

Housekeeper Meals

Activity Centers

Sheltered Workshops

$\begin{array}{rl} & \text { Federal } \\ 536 & 75 \% \\ 652 & 75 \% \\ 1,083 & 75 \% \\ 82 & 75 \% \\ 140 & 75 \% \\ 109 & 75 \% \\ 9 & 75 \% \\ 2 & 75 \%\end{array}$

Federal Match

$$
55.54 \%
$$

$58.32 \%$

$58.15 \%$

$57.03 \%$

$56.03 \%$

$55.40 \%$

$56.35 \%$

$55.04 \%$

$58.76 \%$

Federa 1

$75 \%$

\section{$\$ 96,917$}

93,318

$\$ 2,715,857^{*}$

185,675

15,718

12,529

4,107

56,375

3,153

$\$ 32,302$

21,167

50,120

105,442

7,478

4,584

4,176

1,093

172
Age: No age requirement

Blindness: Must meet SSA

definition of blindness

Income: Below OSIP standards $\$ 204.85$

Resources: Same as OAA

65 or over and eligible for SSI or eligible except for monthly income above SSI

Standards. Must have monthly countable income below PWD monthly assistance standards. Cannot have accumulated reserves over $\$ 1,500$ (or $\$ 2,250$ for a couple at a time, excluding their home.

Recipients of SSI, OSIP or General Assistance or Title $X I X$

Information provided covers persons 65 years of age or older 
d. The Bureaucratic/Managerial-Bureaucratic/

Delivery Interface ( $E$ in Figure 1)

Most of the materials relating to

the development of alternatives for the

reorganization of $\mathrm{DHR}$ are located in the $i$

interface. Typical managerial codings

will be found in PWD internal memos on

reorganization PWD organizational charts,

and Bill drafts for the proposed changes.

An example of a managerially coded

internal memo is one from the Administra-

tor of Public Welfare to the entire PWD

on March 11, 1977 concerning reorganiza-

tion. 1 partial reproduction of the memo

concerning reorganization notes both the

emphasis on managerial goals-smoother

operations, etc., and personnel matters.

The last month has been an absolute flurry with our present and upcoming budget hearings, the unveiling by Governor Straub of our proposed national welfare reform plan (more about this later) and the day-to-day business of keeping PWD wheels turning.

The main topic for talk these days seems to be our reorganization. Frankly, I'm still working on the last bits and pieces hopins to achieve a smoother interface within and between sections. But let me tell you why I jumped in, feet first, 
to reorganize the division with just a few months tenure under my belt. It seemed as if everyday I was called upon to put out forest fires...brush fires I could have handled... but forest fires were just too much. So I looked at the what, the why, the where and the how... and I felt compelled to restructure a division that has a tremendous potential.

Now with our six sections (PERSONNEL MANAGEMLIT AND DEVELOPMENT, HFALTH AND SOCIAL SERVICES, INCOME MAINTENANCE, BUSINESS SERVICES, OPERATIONS REVIEW AND FIEID OPERATIONS), we have a much clearer relationship between the field and programs. We also have a clearer definition between functions and responsibilities. And, finally, I think we now have a rational grouping of like functions and responsibilities plus the workload has been equalized a bit better.

I know it's been a hectic and unsettling time for some-an exciting time for others. People have been shifted from one unit to another--from one section to another--from one floor to another. And I undergtand there's a rumor floating around about massive lay-offs. Nonsense! I might be reshuffling but I'm not laying off anyone. Due to budgetary constraints, some vacant positions might be frozen until the end of this biennium but one thing I do know--I need all the staff I have, I need all the support you can give me, I want to make your job more pleasant.

The flow chart outlining the new or-

ganizational format is also a typical

managerially coded document; its emphasis

is on the hierarchial structure rather than

on an analysis of the operative relation-

ships that would be characteristic of a

flow chart framed in an information code. 


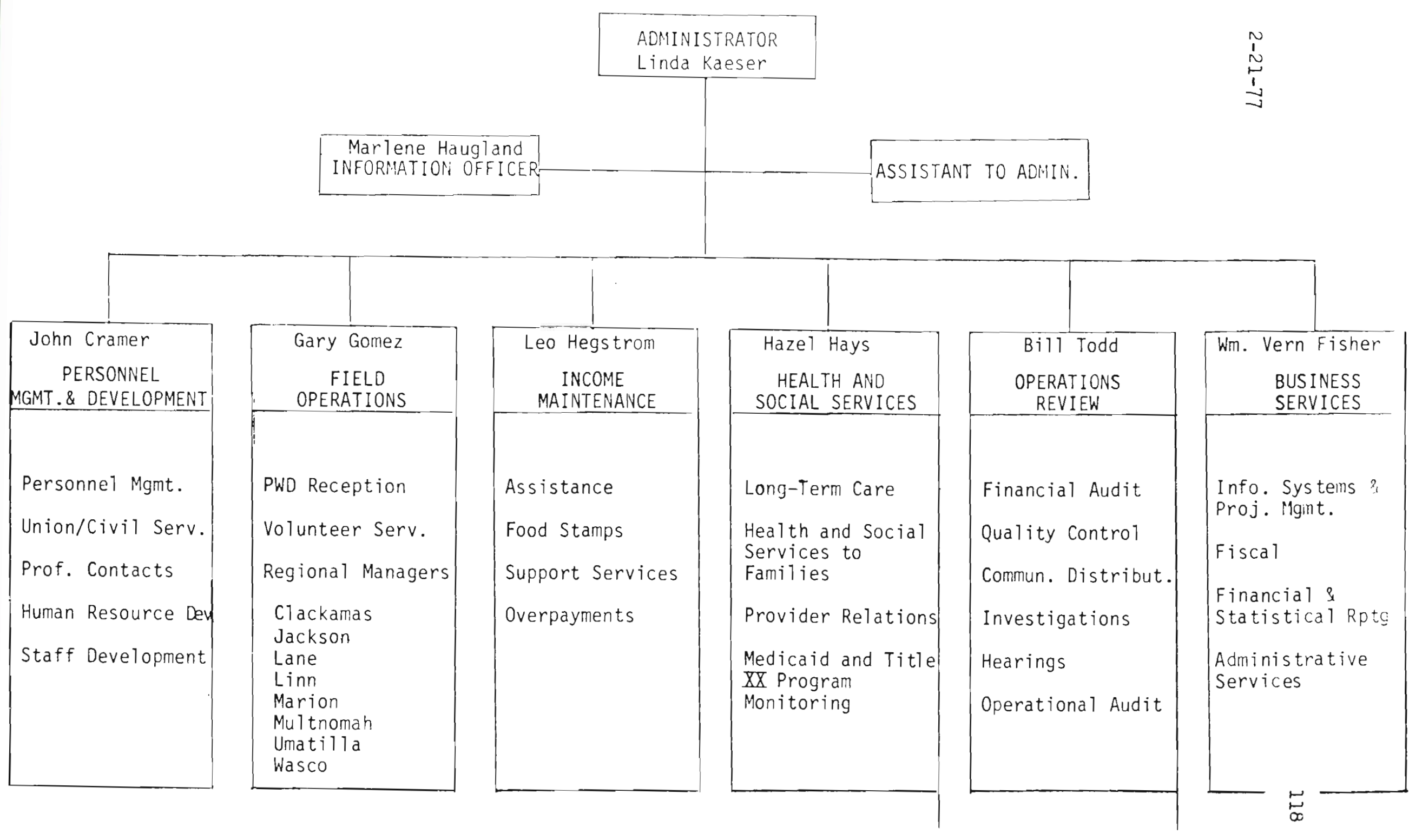


The Bill draft furnishes another example of managerial coding in that it expresses the managerial concepts that are desired by Governor's Committee on Aging when they are seeking support from DHR officials before the bill is sent to Legislative Council for translation into legal form. While seeking support, the GCOA operated in a managerial code in order to seek to protect their interests within the bureaucratic structure. 
The following amendments and suggestions are presented for incorporation in a new bill, a revision of House Bill 3133, which was introduced in the 1975 legislation by the House Committee on Aging, chaired by Representative Ralph Groener. The bill is an act relating to senior services and senior citizens. Section 1. The Governor's Commission on Aging is created. The Commission shall consist of 19 members for terms of three years. Prior to making appointments, the Governor shall request and consider recommendations from senior organizations in the State of Oregon.

The Governor shall designate a member to serve at his pleasure as chairman for a term of three years with such duties as the Governor shall prescribe.

The membership of the Commission shall be composed of members broadly representative of major voluntary agencies who are experienced in or have demonstrated particular interest in the needs of the elderly and shall also include ten members who are consumers of services under the aging programs, including low income and minority older persons at least in proportion to the number of minority and older persons in the State of Oregon.

The Governor's Commission on Aging shall be granted statutory authority to review budgets of public agencies' senior citizen programs, recommendations on such budgets, review of and recommendations on senior service programs, analysis and gaps in such services, and suggestions on remedying them, alerting the private and public sectors on new trends and developments of aging, state-wide advocacy, and innovative approaches.

The Governor's Commission on Aging shall have legal authority and shall act on these matters. It shall be responsible to the Governor's Office for senior citizeng affairs. It shall also bring to the attention of the Director of the Department of Human Resources, senior citizens' affairs, and trends and needs. The special assistant on senior services within the Department of Human Resources shall serve as the executive officer of the Governor's Commission on Aging.

All special programs on aging within the Department of Human Resources shall be united within the new division of aging within the Department of Human Resources. The Division on Aging shall be headed by an assistant administrator for aging in the Department of Human Resources Director's Office.

Within this Division of Aging shall be located the special assistant on senior services and the manager of the state program on aging. They shall report directly to the assistant administrator of aging. 
An ombudsman on aging shall be created in the Governor's office. Adrocacy of and for the aging shall be located in the Governor's office. The ombudsman on aging shall have the responsibility of protecting and furthering the interests of the aged in relationship to the public agencies and private programs in the State. 
e. Bureaucratic/Delivery-Public/Client

Interface (C in Figure 1)

Of all of the documentary evidence utilized to illustrate the coding types, the materials here are the most straight forward. The forms which embody information codes used to deternine eligibility for programs are almost classic examples of an information code with a series of more or less clear criteria for the evaluation of a client's position vis a vie a program. The excerpt from form PWD 415B is a good example of the use of information codes to determine eligibility. 


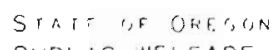

PUBLIC, NELFARE DIVISION
PWO 4 ISB

APPLICATION FOR OREGON MEDICAL ASSISTANCE

E SUPPLEMENTAL INCOME PROGRAM

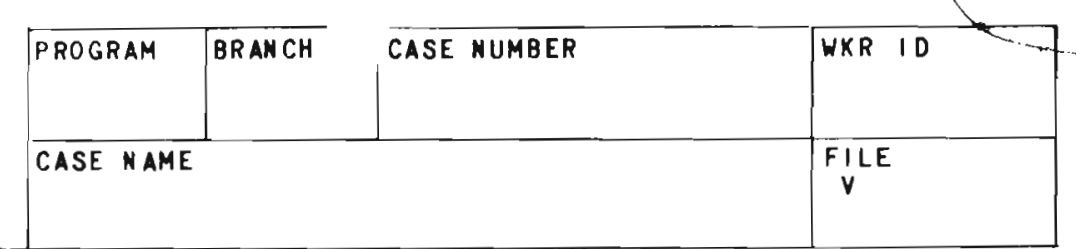

NOTICE: PATMENT IS MADE ONLY IF YOU ARE ELIGIBLE POR SOPPLEMENTAL SECURITY INCOME (SSI) BENEPITS

FULL NAME:

TELEPHONE :

MAILING ADDRESS:

ZIP CODE:

DATE FORM REQUESTED:

RETURNED:

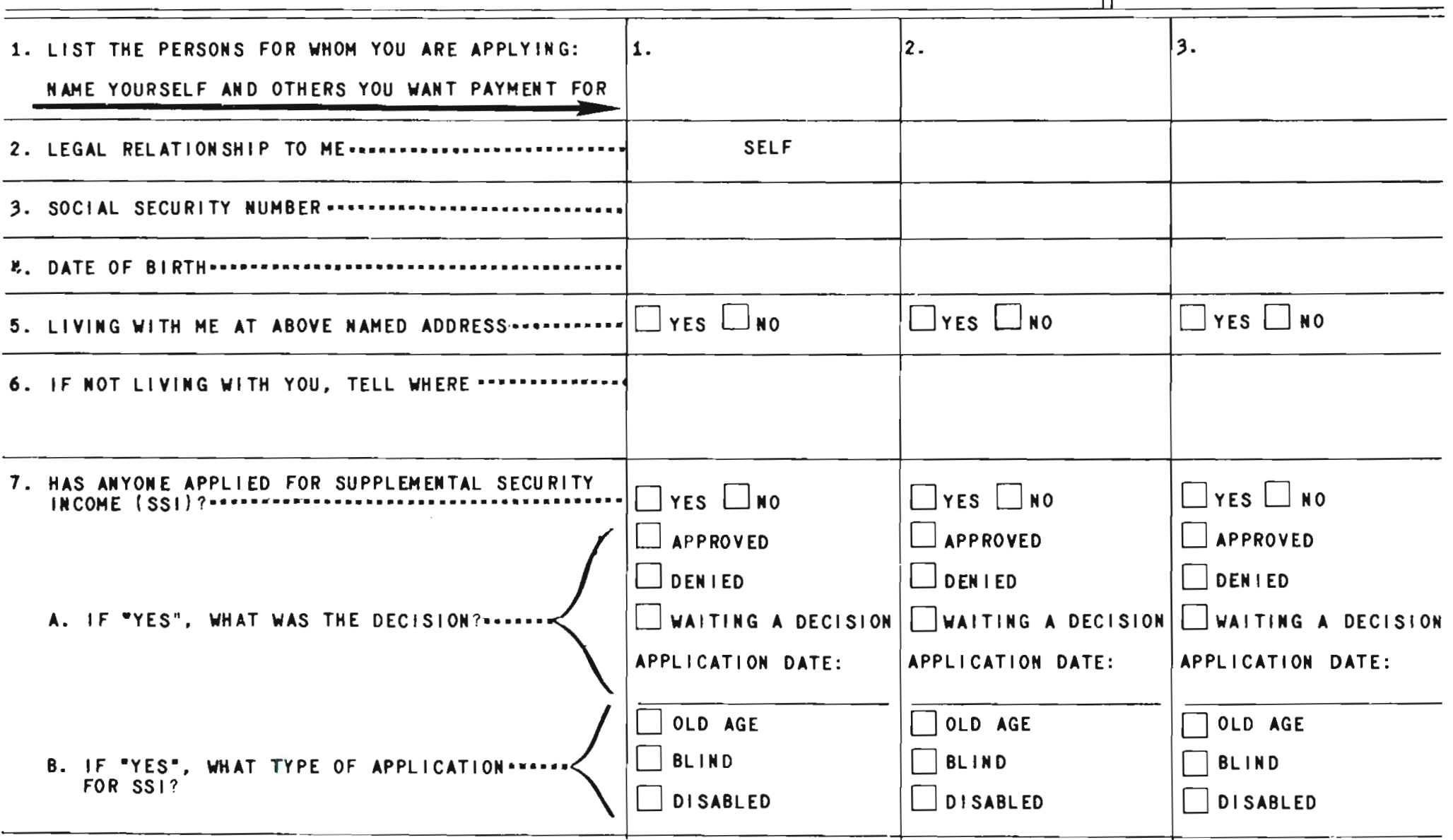




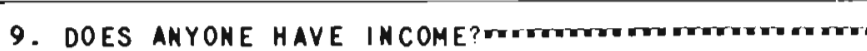
IF "YES", CHECK the aVERAge amOUnt PER MONTH WHERE DOES THE MONEY COME FROM?

20. IS ANYOHE ON A SPECIAL DIET BY DOCTORS ORDERS? if "YES", TELL US

A. KIND OF DIET:

B. DOCTOR'S MAME AMD ADDRESS:

11. DOES anyone haVe ahy OF THESE InSURANCES? IF SO, PLEASE CHECK
BOTH LIVING \& MEDICAL EXPENSES

MEDICAL ONLY

FOOD STAMPS

BOTH LIVIMG \& MEDICAL EXPENSES

MEDICAL ONLY

$\square$ FOOD STAMPS

$\square$ YES $\square$ NO

$\square$ \$0 thru $\$ 7.50$

$\square \$ 7.50$ thru $\$ 19$

$\square \$ 20$ or more

$\square$ yES $\square$ No

LIFE INS.

$\square$ BURIAL INS.

$\square$ YES $\square$ NO

$\square$ so thru $\$ 7.50$

$\square \$ 7.50$ thru $\$ 29$

$\square \$ 20$ or more

$\square$ YES $\square$ No

$\square$ MEDICARE

$\square$ OTHER HEALTH INS. $\square$ LIFE INS.

$\square$ BURIAL INS.
BOTH LI VING \& MEDICAL EXPENSES

$\square$ MEDICAL ONLY

FOOD STAMPS

YES $\square$ NO

$\square \$ 0$ thru $\$ 7.50$

$\$ 7.50$ thru $\$ 29$

$\square 20$ or more

$\square$ YEs $\square$ No

\begin{tabular}{l}
$\square$ \\
\hline$\square$ MEOICARE \\
$\square$ OTHER HEALTH INS. \\
$\square$ LIFE INS. \\
$\square$ BURIAL INS.
\end{tabular}


However, this data is not sufficient alone in deciding in grey areas. Here the inputs from the forms are evaluated by the Rules and Regulations of the PWD, and these being managerially coded often need technical assistance from the information oriented opinions of the Attorney General. Indeed, it was the poor interface in these areas that led to public outcry that in turn led to the reorganization of the DHR. This short review of the types of documentation and their place in the model will permit us to proceed with an analysio of the various reorganization alternatives.

\section{Analysis of Decision Altematives}

The latent function of elderly programs and the other apparatus developed as counterweights to PWD has led to the development of a series of alternatives possible decisions in reorganization. Since these alternatives are the focus of this analysis our presentation will include both a manifest and latent political effect as well as an analysis of the coding wherein the alternatives are presented. 
a. Alternative One: Bureaucratized DHR

This alternative would extend the bureaucratic control to include all of the aspects of DHR, in effect extending DHR control over PWD and Elderly Programs and SPOA. Manifestly the situation would be presented in managerial language, most likely in a traditional mode. The agrunents would all be along lines of rationalization of function; tighter control and cost effectiveness. Greater efficiency would be promised. Documents that are framed along these lines are to be found in the presentations of proposals for reorganization from the deputy of $D H R$ who is a career bureaucrat.

The Deputy Director of DHR addressed the Governor's Committee on Aging in April of 1977. In his presentation he outlined the proposed reorganization that sought the above aims. His remarks emphasized efficiency in operations and adminiatrative simplification and the clarification of responsibilities that would accrue if the DHR were to include PWD, SPOA and Elderly 
Programs under one bureaucratic structure. (Field notes GCOA meeting April 1977)

Such a proposal, when presented in a managerial code package, will probably not receive support at the legislative interface unless there is far greater input along fiscal lines to demonstrate that cost reductions will indeed be made.

b. Alternative Two: No Changes from Current Organization

This altermative would represent the failure of the politicians to control DHR, as well as DHR's failure to extend its domain over PWD, with Elderly Programs and SPOA remaining independent of control by DHR. The selection of this alternative is thus latently a standoff. Manifestly, the programs for seniors would continue to serve as a countervailing power base, but their effectiveness would only last as long as Federal interest in aging continued to be in style. Proposals along lines to maintain the current status, assuming that the power balance does not shift to permit another alternative-would probably be 
phrased in general systems theory codes. Currently the independence and autonomy of many of the programs for senior citizens is supported by the public speeches and appearances of the governor and the advocacy role of the Governor's Committee on aging. This latter body is an instrument that operates at the politician/ representative-public/voter interface in support of various interests in legislation and proposed actions.

c. Altemative Three: Reorganization with Policy Non Bureaucratic (IC 2549) Politically this alternative would see DHR control PWD, all of the elderly programs mentioned above, etc., under unclassified personnel in policy forming positions. These latter thus serve at "the pleasure of the govermor", e.g., not civil service, but political appointments, and are thus separate from the bureaucracy. The manifest statements of this reorganization would be similar to those expressed by alternative one-rationalization, cost effectiveness, etc. However, the latent 
political meaning of this alternative would be that the politicians-in the Executive departments-had reestablished control over the policy areas by forcing PWD to become a division of DHR. Separate division for the elderly programs would insure that public advocacy would continue within the department. This direct access to Governor and Head of DHR would tend to break the control of information that is characteristic of traditional bureaucracy. Budget control would now be in hands of Director of DHR, not PWD.

The most effective language form for this proposal would be to frame the presentation into an information code. Supporting testimony to the legislature should be in these terms, not in managerial codes. An example of successful packaging of a proposal in information terms as against managerial codes when interfacing with the legislative/fiscal interface may be found in the reception given to the Summary of Elderly presented in information codes (Programs in DHR 
dated March 17, 1977, page 115) as against

a series of managerial codes on the same subject (Joint Senate-House Committee on Aging, January 18, 1977, page 116).

\section{d. Alternative Four: Reorganization with}

Limited Bureaucracy and GCOA as a

Counterweight

Finally, there is an alternative that would make Elderly Programs and SPOA a division under DHR. PWD would also be a division, but would remain essentially separate. DHR would thus utilizes some funds from Elderly Programs as a counterweight to PWD, but would also have the Governor's Committee serve to review all materials that affect the services to the elderlyin effect a Commission with review powers. Politically this alternative has little chance as it stands. However, as it is the alternative proposed by the public (through GCOA), it will have some impact on the final plan that evolves. It has already led to a modification of the original form of the bill that incorporated alternative three (Revised Form LC 2549 of 
Marx's Bil1). Much of the success that the GCOA has had may be found in their more or less consistent success in pack= aging their proposals. In all of the examples examined, this group has a better record of presenting data along lines that the model predicts as most likely to succeed in translation. Their ability to do this, thus, makes GCOA an effective counterweight to the bureaucracy.

The model thus predicts a number of possibilities with reference to these alternatives.

1. The bureaucratization of DHR-alternative one-will fail, both because of political pressures against such a course, and because proposals that seek this end are framed in an inappropriate managerial code. An information code package for this proposal would increase its chances, but probably not enough to achieve this altemative.

2. The standoff situation-alternative two-may occur, and if it does the 
success of GCOA in presenting its

materials in appropriate codes (usually

information or general systems codes)

will continue to make this agency the

major vehicle to block the bureaucratic

designs embodied in the first alterna-

tive.

3. The reorganization with limitations on bureaucracy has the greatest chance of passage. This alternative will increase its chance of acceptance if the legislator (Rep. Marx) in seeking support presents his material in appropriate codes: information codes for other legislators; managerial codes for the bureaucracy, and general systems theory codes for the public.

4. This alternative has already had some success in modifying the third alternative to retain GCOA (LC 2549). It may well succed in attaining its proposed review powers, but in an advisory capacity only. The fact that GCOA is successfully applying the coded procedures demanded by the model may be 
taken as evidence of verification of the predictions that correct forms of proposal packaging leads to increased chances of success. If review powers are granted, i.e., GCOA becomes a Commission then this will represent a victory by the bureaucracy over the advocacy role. The most likely outcome is that GCOA will remain in an advising capacity with some additional Budget/Program review responsibility over programs receiving Senior Citizens. 
CHAPTER V

TMPLICATIONS OF THE MODEL FOR SOCIAL PLANNING

The model described in this paper has several important features that are of import for social planning. In this chapter we shall seek to make these features explicit as well as to note the Iimitations of the model and suggest possible future research development of the approaches developed in the previous chapters.

Among the single most important characteristics of the model is universality with respect to the level of analysis. By universality with respect to the level of analysis, we mean that this model is applicable both within and between an agency context. At the present time inter and intra agency analysis depends upon different modeling approaches. (Neghandi, 1975) The model proposed here forms a single frame of reference for the analysis of deciaion making; the three basic subsystems exist at all levels of inter or intra agency contact. The linguistic codes used between interfaces are not levelspecific, but rather are a function of the particular interface concerned. Since the three basic subsystems and the six interfaces are thus general in nature, the coding problems identified and discussed In this presentation are also general in nature.

This generality of approach, or universality of the model for all inter and intra agency contexts is important for planners in that it not only eliminates the plethora of modeling that now clouds decision making and thus saves costs in the planning effort; it 
facilitates communications amongst planners themselves. This latter aspect is important; planners often weaken their efforts by not achieving a comonality amongst themselves-each group being tied to a partioular approach or technique that is at odds with the assumptions of other approaches and techniques.

This diversity of current approaches and their mutual antipathy was discussed in Chapter I. The systems approach, and the model that was derived from it however, permits a commonality of communications amongst planners. It identifies the particular locus for a planner and guides him, at least potentially, into the requisite needs for the translation of his ideas into the proper code so that his concepts may be considered rather than suffer rejection on coding grounds alone。

A second important facet of the model is that it is able to analyse processes rather than the products of change. Other modeling approaches-value theory, conflict theory, and structural functional theory all are post hoc. That is, their analytical outputs depend upon the completion of the action being considered before they can provide a basis for planning. The ability of planning efforts based upon these theories is woefully lacking in predictive (Levy, 1968)。 The ability of a model to predict is a fundamental feature for its acceptability as a scientific construct (Popper, 1965; Braithwaite, 1953). However, it is important to remember the limits of the predictions made by the model. The model only claims to predict the outcomes of the exchanges or translations made over the interfaces 
identified in the model. That is, it only predicts that material formulated in a code appropriate to an interface will possess a greater potential of accomplishing communication across that interface than if it is formulated in a code that is inappropriate. The model does not predict the final outcome of a political exchange over these interfaces. Thus, with respect to the alternative courses of action delineated in chapter IV regarding the reorganization of the Department of Human Resources, the model only predicts the potential efficacy of framing the proposals in the appropriate code; other political factors not related to the communications that occur over the interfaces will be far more important in determining the final outcome. The model does predict that proposals framed in the appropriate codes will increase the probability of the acceptance of that alternative. This was demonstrated, and the prediction was partially verified, when the third alternative (Marx bill in original form was modified to include proposals of alternative four in LC 2549).

The two major features of the model, its universality with respect to level of analysis and its ability to predict, provides the social planner with potentially useful insights into the decision making process. In utilizing the model the planner may accomplish a number of important tasks in both conceptualizing the problem and designing his plan to include the maximal potential for implementation. This latter factor is often lost in a planning effort (Bolan and Nuttall, 1975; and for an example where this factor was ignored- 
Pivan and Cloward, 1975).

Among these potential applications for social planning then

It is possible to identify the following:

1. Greater ability on the part of the planner to conceptualize the task as a whole. The model, based as it is on a systems approach emphasizes the need, visualize the suggested proposal as affecting the entire network of a social service system-the political factor, the public factor and the bureaucratic-administrative factor. Any proposal in social planning will need to pass through all three areas; planning cannot be done effectively within one sphere alone.

2. Greater ability on the part of the planner to conceptualize the frame of reference that is used by members of each subsystem of the whole. Social planning, affecting all aspects of the whole on its formulations, can when the model is applied gain some insight into the differences between how a problem is understood by the members of the three subsystems. What appears as a problem to a planner in the bureaucratic subsystem, may well appear as a vital feature of an operative 
system by a member of the political subsystem. The application of the model thus gives the planner the ability to frame the problem and proposed solutions within the context of the whole social service system.

3. Greater ability on the part of the social planner to frame his proposal in a code package that will assure maximal communication of his proposals to all segments of the system. The entire purpose of the model is, of course, to enhance the chances of acceptance of a planning proposal on the part of the public, administrative and political sectors. The research above has illustrated the role of appropriate coding in such implemenative efforts.

4. Finally there is a greater ability on the part of the social planner to continue to administer a program with adequate support since communications about the programs operations and needs for possible amendments to the program-once instituted-may now be framed in an appropriate code as indicated by the model. 


\section{Areas for Further Research}

While the model as presented is a valuable tool for social planners in its present form, there are several areas that further research and development might be utilized in order to extend and refine the model's capabilities. Many of the following suggested areas of development were not accomplished in this initial effort because of budget and temporal restrictions.

The initial area for extension of the model probably lies in the refining of the test instrument. The rough, and somewhat subjective analysis of documentary evidences of coding procedures and usage could be extended to include a well developed test instrument where individuals located within a particular role position within the system could be tested as to the degree he or she was influenced by a particular code. If possible, personnel upon shifting roles, could be retested and the degree of change in code usage and preference could then the accurately tied to a position within the social service system structure. It might well be that correlations between code preferences correlate with other psychological and/or social psychological test instruments in a predictable manner so that evidence gathered in one area could have a greater analytical power through linking a series of results-viz., if a high score on an authoritarism scale ( $F$ scale) (Adorno et al, 1946) has a high correlation with a preference for managerial languages or codes, then managerial language or code usage is indicative of other psychosocial behaviors than mere position within a system structure alone 
would indicate.

Simflar analytical efforts could be tied together in reverse (provided that the correlation was indeed there) 80 that planners who wish to write job descriptions within a proposal could specify certain psychological test results as being preferable for persons to fill certain positions. Thus if, for example, a high $F$ score did have a high correlation with a managerial code, and the position was one that the planner expected to have change within the proposal, then persons with low F scores, but with minimal capability in managerial languages might prove optimal.

Aside from these applications of a quantified sort, the model also serves to provide a sociological context to content analysis beyond the ideological interpretation that has been the case with most such studies. (Bendix and Lipset, 1966) The model is in fact an adaptation of content analysis procedures, but the locus of the codes within an administrative-service delivery-political network is beyond the previous applications that have so far been made in this area. Nathan Leites application of a modified, but non quantifiable psycho-analytically based, "operational code" for the analysis of Soviet decision makers in 1951 did not lend itself to extension as it was case specific, and non replicable. The model presented here permits the analyais of the operative codes of persons or institutions that are in particular interface with each other regardless of the scale of the unit involved, and has the potential for quantification and measurement. 
If improved instruments were indeed to be made available, then in addition to forming a contextual basis for the interpretation of social and paychological test materials, the model could also be applied to an array of types of change situations beyond the limited scope of a reorganization effort as utilized here. Most social institutional situations, at least in complex societies, include the three agpects that form the basis of the model-political, public and administrative. If, upon application to situations where change included not only shifts in procedures, as in the reorganization instance, but technological innovations or basic changes or differences in political procedures, then the value of the model's universality might well be demonstrated, or its limitations duly noted. 


\section{BIBLIOGRA PHY}

\section{Books and Articles}

Adorno, Theodore et al.

1950 The Authoritarian Personality, New York, MacMillan.

Alinsky, Sol

1967 Revelry for Radicals, Now York, Vintage.

Arnstein, Sherry

1969 "A Ladder of Citizen Participation", in Journal of the Institute of American Planners, 35, p. 216-24.

Aron, Raymond

1968

Main Currents in Sociological Thought, Vols. 1 and II, New York, Anchor Books.

Ashby, Ross

$1956 \mathrm{a}$ "Societal Constraints and the Law of Requisite Variety", in Buckley (ed.) Modern Systems Research for the Behavioral Scientist, Chicago, Aldine, p. 129-136.

1956b "Regulation and Control", in Buckley (ed.) Modern Systems Research for the Behavioral Scientist,

1960 Design for a Brain, New York, Wiley.

1962 "Principles of the Self-Organizing Systems", in Buckley (ed.) Modern Systems Kesearch for the Behavioral Scientist, Chicago, Aldine, p. 108-122.

Barnes, Henry E.

1948 The History of Sociological Theory, Chicago, University of Chicago Press.

Bateson, Gregory

1958 Navin, 2nd Edition, Stanford, Palo Alto, University Press.

1972 Steps Towards an Ecology of Mind, New York, Ballantine.

Bateson, Gregory and E. Reusch

1951 Communications, New York, Norton. 
Bendix, Retnhardt and Seymour Lipset

1963 Social Mobility in Industrial Society, Palo Alto, Stanford Untversity Press.

1966 Class, Status and Power, New York, Free Press.

Blau, Peter

1962 Formal Organization, San Francisco, Chandler.

1963 Bureaucracy, New York, Random House.

Boas, George

1969 The History of Ideas, New York, Scribners.

Bolin, Richard and Ronald Nuttall

1975 Urban Planning and Politics, Lexington, Mass., Beath and Company.

Brady, Rooney

1973 "MBO Goes to Work in the Public Sector" in Harvard

Business Review, 42, March-April, p. 65-74.

Braithwaite, R. B.

1960 Scientific Explanation, New York, Torch Books.

Braybrooke, D. and C. E. Lindbloom

1963 A Strategy of Decision, New York, Free Press.

Buckley, Walter (ed.)

1968 Modern Systems Research for Behavioral Scientist, Chicago, Aldine.

Cassiere, Ernst

1953

Substance and Function and Einstein's Theory of

Relativity, New York, Dover.

Coser, Lewis

1956 The Function of Social Conflict, New York, Free Press.

1967 Political Sociology, New York, T'orch Books.

Crossland, P.

1964 "The Future of Socialism in Socialist Thought", in Socialist Thought, Fried and Sanders, eds., New York, Anchor Books.

Dahrendorf, N.

1967 "Class and Class Conflict", in Industrial Society,

R. Bendix, ed., Palo Alto, Stanford University Press. 
Demerath, N. J. and h. A. Peterson, eds.

1967 System, Change and Conflict, New York, Free Press.

Drucker, Peter

1954 The Yractice of Management, New York, Harper.

Eisenstadt, S. N。

1956 From Generation to Generation, New York, Free Press.

Flannery, E。 et al.

1971 "Farming Systems and Political in Ancient Oaxaca", in Struever, ed., Prehistoric Agriculture, New York, Natural History Press.

Fried, Jacob and Paul Molnar

n.d. A Transdisciplinary Model of Society and Culture,

Gilbert, Neil and Earry Specht

1974 Dimensions of Social Welfare Policy, Bnglewood Cliffs,

Hetrich, James

1963 "Mathematical Models in Capital Budgeting", in Bursh

and Chapman, eds., New Decision Making Tools for

Managers, New York, New American Library.

Hofstadter, Richard

1952 Social Darwinism in America, Boston, Beacon Press.

Jammer, Max

1962 Concepts of Force, New York, Torch Books.

Kahn, Alfred

1969 Theory and Practice of Social Planning, New York, Russell Sage Foundation.

1970 "Perspectives on Access to Social Service", in Social Work, 15, 2, p. 95-101.

Kast, J. and Rosenzweig

1972 "A Modern View: A Systems Approach", in Systems

Bohavior, J. L. Bishon, ed., New York, The Open

Jniversity Press, Harper and Row, p. 14-28.

Kaufman, Herbert

1968 "The Administrative Function", in The Encyclopedia

of Social Sciences, New York, MacMillan. 
Klir, George S.

1969 An Approach to General Systems Theory, New York,

Van Nostrand-Reinhold.

Kohler, Wolfgang

1947 Gestalt Psychology, New York, Liverwright.

Lang, Norton

1968

"Administrative Process", in Encyclopedia of Social

Sciences, New York, MrcMillan.

Levinson, Harry

1970 "Management by Whose Objectives?" Harvard Business

Review, 48, July-August, p. 125-134.

Levy, Marion

1968

"Functionalism", in Encyclopedia of Social Sciences,

New York, MacMillien.

Lingenfelter, Sherwood G.

1975 Yap Political Leadership and Political Change, Honolulu, University of Hawaii Press.

Lipset, Seymour

1954 Union Democracy, New York, Anchor Books.

Lovejoy, Arthur

1936 The Great Chain of Being, Cambridge, Harvard

University Press.

McKeon, Richard

1954 Thought, Action and Passion, Chicago, University of Chicago Press.

Malinowski, Bronislaw

1922 Argonauts of the Western Pacific, New York, Dutton.

Mannheim, Karl

1936

Ideology and Utopia, New York, Harvest Books.

Martindale, Don

1960

The Nature and Types of Sociological Theory,

Cambridge, Evenside Press.

Marx, Karl

1932

"The Communist Manifesto", in Lemer, ed., Capital and Other Major Writings, New York, Random House. 
Mayer, Ernst

1970 Populations, Species and Evolution, London, Oxford.

Mayo, Elton

1946 The Human Problems of Industrial Civilization, Cambridge, Harvard University Press.

Medina, Celia and M. Reyes

1976 "Dilemmas of Chicana Counselors", in Social Work, 21, \#26, November, p. 515-517.

Merton, Robert $\mathrm{K}$.

1968 Social Theory and Social Structure, 2nd ed., New

York, Free Press.

Miller, Robert

1963 "How to Plan and Control with PERT", in Bursch and

Chapman, eds., New Decision Making Tools for Managers,

New York, New American Library.

Morris, Charles

1956 Varieties of Human Values, Chicago, University of

Chicago Press.

Morris, Richard and Martin Rein

1969 Dilemmas of Social Reform, New York, Atherton Press.

Morris, Robert and Robert Binstock

1966 Feasible Planning for Social Change, New York,

Columbia University Press.

Murdock, George Peter

1949 Social Structure, New York, Free Press.

Nadel, S. F。 1958 The Theory of Social Structure, New York, Free Press.

Neghandi, E. R., ed.

1957 Interorganizational Theory, Kent, Unio, Kent State University Press.

Pareto, Vilfredo 1966 Sociological Writings, New York, Praeger.

Parsons, Talcot

1951 The Social System, Glencoe, The Free Press.

Parsons, T. and E. Shils

1956 Towards a General Theory of Action, Cambridge, Harvard University Press. 
Piven and Cloward

1971 Regulating the Poor, New York, Pantheon Books.

Pollack, Irwin

1968 "Information Theory", in Encyclopedia of Social

Sciences, New York, MacMillan.

Popper, Karl

1968 Conjectures and Refutations, New Yor, Torch Books.

Raider, Melvin C.

1975 "An Evaluation of Management by Objective", in

Social Casework, February, p. 79-83.

Rapaport, Anatole

1960 Fights, Games and Debateg, Ann Arbor, University of Michigan Press.

1974 Conflict, Baltimore, Penguin Books.

Redfield, Robert

1946 The Folk Culture of Yucatan, Chicago, University of Chicago Press.

1956a The Little Community, Chicago, University of Chicago Press.

1956 b Tepoztlan, Chicago, Univergity of Chicago Press.

Reif, W. and J. Bassford

1973 "What MBO Really Is", in Business Borizons, June.

Riley, M. W. and C. S. Stoll

1968 "Content Analysis" in Encyclopedia of Social Sciences,

New York, MacMillan.

Sahal, Devadendra

1976 "Homeoratetic Regulation and Structural Stability", in Cybernetics.

Simon, Herbert

1964 "Approaching the Theory of Management", in H. Kuntz, ed., Toward a Tnified Theory of Management, New York, McGraw-Hill.

1968 "Administration", in Encyclopedia of Social Sciences, New York, MacMililin. 
Singer, Milton

1972

When a Great Tradition Changes, New York, Praeger.

Sorokin, Pitirim

1963 Kodern Historical and Social Philosophy, New York, Dover.

Taylor, Frederick W.

1911 The Principles of Scientific Management, New York, Harper.

Trattner, $W$.

1974 From Poor Law to Welfare State, New York, Free Press.

von Bertlanffy, Ludwig

1962 Modern Theories of Development, New York, I'orch Books.

1972 "General Systems Theory: A Critical Review", in

Bishon and Peters, eds., Systems Behavior, New York,

Open University Press-Harper and Row.

von Forrester, Heinz, ed.

1969 Purposive Systems, New York, Spartan Books.

Warner, Lloyd

1958

The American Dream, Chicago, University of Chicago

Pres8.

Warren, Roland

1967

"The Interorganizational Field as a Focus of

Investigation", in Administrative Sciences

Quarterly, $12, \mathrm{p} .3 \overline{46-419}$.

Weaver, Warren

1949

"Mathematics of Communications", in Scientific

American, July.

Weber, Max

1946

From Max Weber, Gerth and Mills, eds., London, Oxford.

weiner, Norbert

196

Cybernetics, 2nd Edition, Cambridge, Mass., MIT Press.

Wiehe, Vernon $k$. 1973

"Management by Objectives in a Family Service Agency", in Social Casework, March, p. 142-146. 
Doounents Cited

Opinion Request, OP-3661 by DHR to Attorney General.

Minutes of Sub Committees \#4, Ways and Means, 5-20-1975.

Press Release of GCOA.

Minutes of Meotings of Governor's Committee on Aging (GCOA).

Hearing8 House Comittee on Aging, January 20, 1977. Testimony HB 2040.

Testimony. Director DHR to Joint Senate-House Comittees on Aging, January 18, 1977.

Testimony。Administratory SPOA - Joint Senate-House Committee on Aging, January 18, 1977.

Sumary Statement of Elderly Programs in DHR. Prepared for Joint House-Senate Committes on Aging, March 17, 1977.

PWD Form \#415B, revised 11/73.

Minutes, GCOA, April, 1977.

Joint Senate-House Committees on Aging, January 18, 1977.

HB 3285 - Bob Marx

LC 2514, revised HB, Box Marx. 